\title{
Design, Fabrication, and Characterization of Thermal and Optical Properties of Nano-Composite Self- Cleaning Smart Window
}

Mehdi Jafari Vardanjani ( $\sim$ mehdijafari@ut.ac.ir)

Technical and Vocational University

Mehdi Karevan

Isfahan University of Technology

\section{Research Article}

Keywords: Smart window, Nano-fluid, Nano-composite, Light transmission, Self-cleaning

Posted Date: March 3rd, 2021

DOI: https://doi.org/10.21203/rs.3.rs-232029/v1

License: (c) (1) This work is licensed under a Creative Commons Attribution 4.0 International License.

Read Full License

Version of Record: A version of this preprint was published at Optical and Quantum Electronics on October 11th, 2021. See the published version at https://doi.org/10.1007/s11082-021-03250-x. 


\title{
Design, Fabrication, and Characterization of Thermal and Optical Properties of Nano-Composite Self-Cleaning Smart Window
}

\author{
Mehdi Jafari Vardanjani ${ }^{1^{*}}$, Mehdi Karevan ${ }^{2}$ \\ ${ }^{1}$ Department of Mechanical Engineering, Faculty of Mohajer, Isfahan Branch, Technical and \\ Vocational University (TVU), Isfahan, Iran, mehdijafari@ut.ac.ir \\ ${ }^{2}$ Department of Mechanical Engineering, Isfahan University of Technology, Isfahan, Iran
}

\begin{abstract}
Polymer-based smart windows have recently received attention due to their capabilities in energy consumption reduction. A smart window provides desired optical properties when heated/cooled by using solar energy when the ambient temperature requires regulation. The main issue here is the design and fabrication of such a smart element which is the main axis of the current research. The window in the proposed design operates in such a way that the percentage of light transmission depends on the presence of nanofluid between the two walls and refractive index conformity between the fluid and the polymeric walls; Therefore the percentage of light transmission will be at its minimum value $(45 \%)$ in the absence of fluid and it will be at the maximum value (80\%) at the presence of fluid. The fundamental steps of the present design includes design, fabrication, and characterization of the materials. In this regard experiments to determine the mechanical, physical, structural, optical, and thermal properties of components have been performed after considering, designing, and manufacturing various samples. The results show that the proposed smart offers acceptable performance with a fast switching rate and even more than other similar smart glasses due to the usage of discharge/injection mechanism. In overall, the product can be used as a smart transparent element in various structures such as buildings and even vehicles to regulate energy consumption and/or block the view for security purposes.
\end{abstract}

Keywords: Smart window, Nano-fluid, Nano-composite, Light transmission, Self-cleaning 


\section{Introduction}

Buildings now account for $40 \%$ of energy consumption and consequently $36 \%$ of carbon dioxide emissions according to previous research (Allen, Connelly, Rutherford, \& Wu, 2017). This indicates the major importance of the study of buildings in terms of environment and energy consumption. Currently, standard windows typically waste a third of all energy used for heating and ventilation. Thus efforts have been focused solely on windows, and the use of appropriate technology to reduce this energy loss (Donaldson, 2018). A switchable glass (transparent/opaque) is a logical solution to transmit/reflex solar light based on requirements. These devices are designed to reduce air conditioning costs via sunlight blocking in summer and improve light harvesting during winter. Their fundamental mechanism is based on the tunable optical transmittance of incorporated switchable devices, generally stimulated as a response of an applied energy or changes in environmental conditions (Sala, Gonçalves, Camargo, \& Leite, 2018). The main issue of such devices is to utilize newer technologies and solutions to improve thermal and optical properties of them to compromise fabrication and production costs. Polymer-based smart windows are one of the reasonable elements that can be used in buildings to have the required features in this regard. The economical design and manufacturing capabilities, flexibility, optical/thermal features, and nano-technological compatibilities of polymeric products, are the main reasons of the focus of this study on polymerbased smart windows. These types of smart-windows are of the most controllable products in terms of design, fabrication, and application. Polymer-based smart windows can be comfortably embedded in buildings and vehicles to improve energy consumption, automation, and even safety of them in terms of blocking the sight while required.

Previous studies about smart windows design and application are found to be in different categories ranging from energy consumption management purposes to advanced fabrication methods from which the more important cases are described here in a classified manner.

\subsection{Energy consumption optimization}


Hoffmann et al. (Hoffmann, Lee, \& Clavero, 2014) investigated the effects of temperature change on thermochromic smart windows in a hot-cold climate and a warm and humid region of the United States. It was found that compared to the new standard low-transmisson windows, a low-temperature switching thermochromic window consumes less energy by 10 to 17 percent in the south and west. These results have been verified only in the specific geographical regions which have been examined, however Warwick et al. (Warwick, Ridley, \& Binions, 2014) have analyzed this type of windows under a broader range of conditions in and have proven a 50 percent reduction in energy consumption compared to standard windows.

Thermochromic performance of copolymerized micro-hydrogel particles has also been investigated by adjusting the particle size and the structure (Li, Liu, Feng, \& Fang, 2019) to increase the energy consumption reduction in these type of windows however subtle improvement is obtained and fabrication process of such window is complicated. Regardless of production cost, thermochromic smart windows must be investigated deeper due to their potential application for building automation purposes (Piccolo \& Simone, 2015).

Allen et al. (Allen et al., 2017) gained more control over the absorption of solar energy by considering the variable nature of smart windows, between clear and opaque modes, compared to the fixed behavior of the low emission (LE) window. For example, hydroxypropyl cellulose smart window transmits $74 \%$ of the sun's radiation in the transparent state and only $11 \%$ in the opaque state. This value for the LE window is a fixed value of 53\%. Therefore, during the cold periods of the year, the low percentage of passing through the LE window loses useful solar energy and causes the additional energy required for heating to increase. In contrast, smart windows reduce the amount of energy required by high solar energy (74\%) during the cold season. Although this advantage seems reasonable and practical due to inherent properties of the materials used in smart windows, the exact extent of its superiority over LE windows must be tested in a broader manner.

\subsection{Electrochromic smart windows}


Electrochromic switchable devices (SW) are usually composed of multi-layers of components in which switching process is obtained by oxidation/reduction processes and diffusion of externally activated ions (Baetens, Jelle, \& Gustavsen, 2010). Then some features as rapid switching by external voltage (C.-C. Wu, Liou, \& Diao, 2015) and reflection control can be achieved for these devices. Although this type of device can be valuable, it requires several steps for materials development and layers construction, which might consequently lead to reduced transmittance and limited modulation level (Chen, Cao, Chen, Luo, \& Gao, 2014). Additionally, since they change their optical properties by switching between oxidized and reduced form (Baetens et al., 2010), these electrochemical reactions can have a reduced performance overtime due to unwanted side reactions between the electrolyte and active materials (J. Wang et al., 2014), such as decomposition of electrolytes and efficiency reduction of charge transfer reaction between the electrolyte and active materials (Hu et al., 2016).

\subsection{Other smart windows (Photochromic, gasochromic, etc.)}

The efforts on manufacturing photochromic and gasochromic windows are almost considerable as photochromism has already been utilized in fabrication of smart glasses for years and gasochromism has appeared to be a more reasonable approch than electrochromism (Sala et al., 2018). In this regard, Wu et al. (L. Y. L. Wu, Zhao, Huang, \& Lim, 2017), have used transparent photochromic films for smart window applications by embedding organic photochromic dyes in a sol-gel-based matrix. The degree of connection of the coating matrix and the types of organic groups have had effects on the transmission of visible light and the rate of bleaching. By changing the amount of color concentration in the coating, as well as the thickness of the coating, the amount of light transmission reduction has been adjusted between 30 to $60 \%$. According to the author, this product will significantly reduce the passage of energy in the tropics. It should be noted that the high time of state change, lack of high percentage of transparency, and complexity of the structure are among the disadvantages of this design.

In another study conducted by Feng et al. (Feng et al., 2016), intelligent gasochromic windows were tested for energy efficiency in terms of optical and thermal properties. This was done in more depth 
by simulating energy consumption in a building. This study showed that the best areas to use this type of window are areas with cold winters and hot summers. The use of these areas reduces energy consumption in terms of ventilation, cooling, and heating. Nevertheless, the limitation in geographical location and relatively complex equipment required to produce gas should not be overlooked in this plan.

\subsection{Simulations}

Numerical simulation of the performance of smart windows have not been very common among the researchers yet, however there have been some attempts to perform this task. A numerical study on the performance of a multilayer smart window embedded in water-cooled third-generation solar cells has been conducted by Sabri et al. (Sabry, Eames, Singh, \& Wu, 2014). System optimization parameters such as light concentration ratio and cooling flow (of water) are required to prevent system performance loss due to thermal stresses and high cell temperatures. In this study, detailed modeling of thermal properties of window system was performed using fluid analysis software; Finally, by considering the conductive, convective, and radiative heat transfer mechanisms in the proposed smart window, numerical solution results are presented.

In another study, the effect of passive ventilation system and smart windows has been studied by Khalesi et al. (Javad \& Navid, 2019) in a building adaptable to climatic conditions. The distribution of temperature and air conditions have been investigated for two heat sources, smart windows , and two types of ventilation systems in fluid analysis software. Thermal comfort criteria have also been set by the validated model for smart windows. The results of the analysis show that smart windows are superior in terms of fulfillment of comfort criteria. It was also shown that the temperature difference between floor and ceiling can be reduced by up to $50 \%$ with the help of electrochromic windows.

\subsection{Overview}


Some of the limitations existing in previous studies and products can be summarized as follows:

- Time (seasonal) and spatial (geographical) constraints in achieving useful product efficiency

- High cost of construction

- Structural complexities of used materials

- Complexity of manufacturing the required product and equipment

- Major dependence of state change on thermal energy

- Lack of high transparency

- Long switching duration

- Restriction of the window installation position due to sight blocking when the temperature rises

Here an innovative design of smart windows is provided by harnessing light refraction index conformity and taking the advantage of simple draining/injection system. Thereby, the optical transmittance of the smart windows can be changed between extreme values at any time without the need to reach a switching threshold in response to intense solar heating. The window in the proposed design operates in such a way that the percentage of light passing through the window depends on the presence or absence of fluid (nanofluid) inside the polymeric panel together with the refractive index conformity between these components according to the percentage of nanoparticles in the fluid. Therefore the percentage of light transmission will be at its minimum value (45\%) in the absence of fluid and it will be at the maximum value $(80 \%)$ at the presence of fluid. Characterizing experiments, fabrications steps, and obtained results are explained and discussed in the following sections in detail. 
2. Materials and methods

2.1. Materials

Transparent polymers usually exhibit various optical properties such as tailored emission/absorption properties and/or low/high refractive index. These facts about such polymers attract great interest because of the potential optoelectronic applications (Demir et al., 2007). Hence the polymer used is PMMA. Another reason for choosing this polymer is its availability. PMMA as a transparent polymeric material offers excellent transparency in the visible and near-infrared range (Zettl, Mayer, Klampaftis, \& Richards, 2017). It is often used as an alternative to glass. PMMA has a transmission of more light and much lighter than silica glass. In addition, it is almost easy to find a fluid with a similar light refractive index (n), which can be modified with the desired coating. Nevertheless, PMMA transmits UV light; thus, manufacturers usually apply UV coatings on PMMA to overcome this deficiency (Hammani, Barhoum, \& Bechelany, 2018).

The nanocomposite coating for this purpose is $\mathrm{ZnO}-\mathrm{PMMA} \mathrm{ZnO} \mathrm{NP}$ is a well-known multifunctional inorganic filler that has outstanding properties such as high refractive index, high thermal conductivity, self-cleaning behavior as well as photo-catalytic, antibacterial, and UV-protection properties (Sun, Miyatake, \& Sue, 2007).

In overall , the polymeric component (PMMA) contributes to good processability, transparency, and flexibility, while the NPs $(\mathrm{ZnO})$ provide the desired thermal, and optical properties (Dai Prè, Martucci, Martin, Lavina, \& Di Noto, 2015).

The target fluid is methyl salicylate, which turns to nanofluid after the addition of zinc oxide nanoparticles. Among the important properties of the desired fluid can be mentioned the following:

- The refractive index close to the PMMA; 
- Medium and low viscosity, which is suitable for the state change mechanism,

- High transparency,

- Large boiling point and ignition which makes it stable in the desired temperature range,

- Environmental adaptation (skin contact).

\subsection{Fabrication}

The experimental steps including fabrication process, and characterization tests (Fig. 1) are explained in this section.

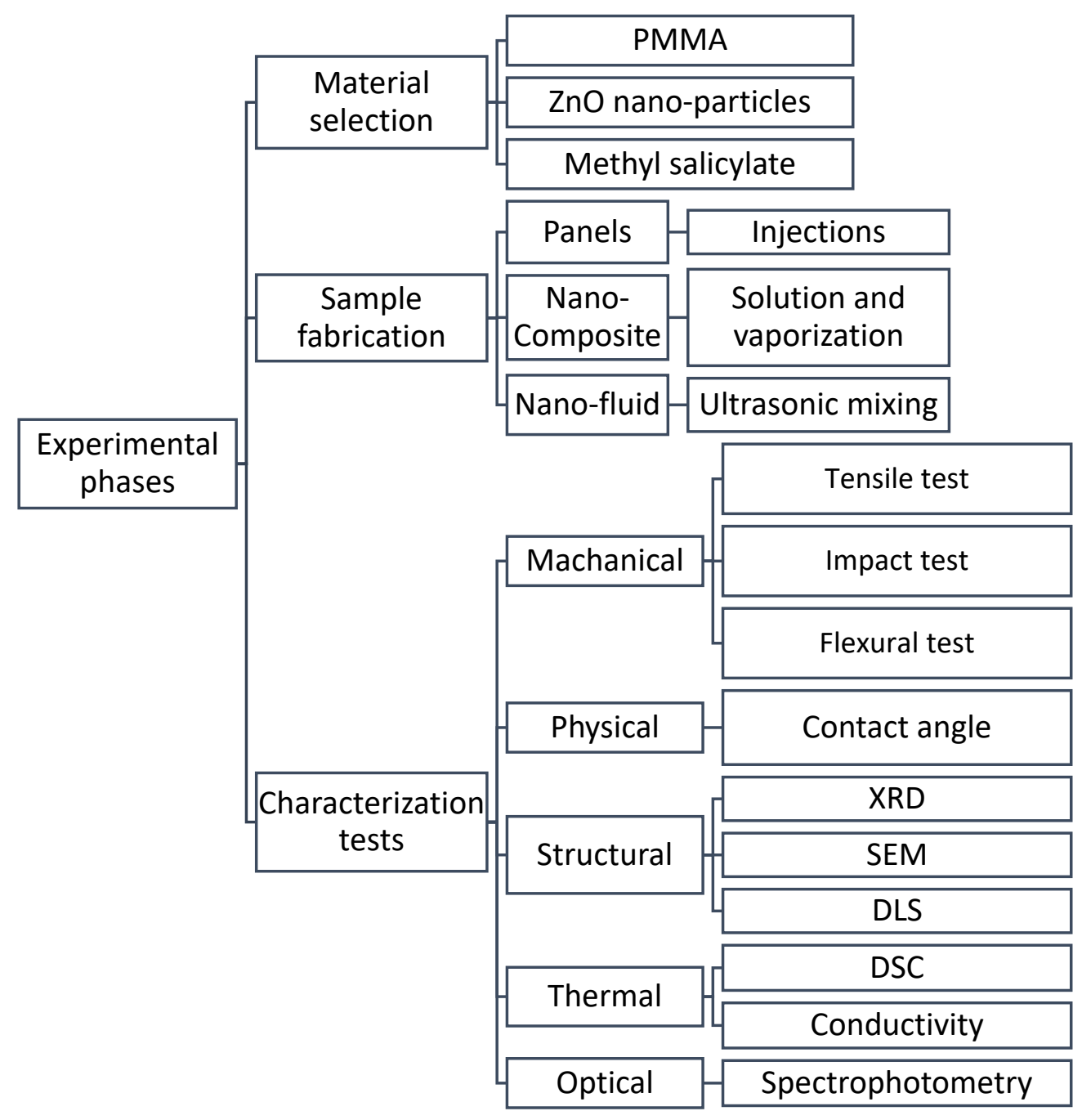

Fig. 1 Experimental steps 
Assembled sample is demonstrated in Fig. 2. The sample is prepared by injecting fluid inside polymeric panel, while external surfaces are covered by nano-composite film.

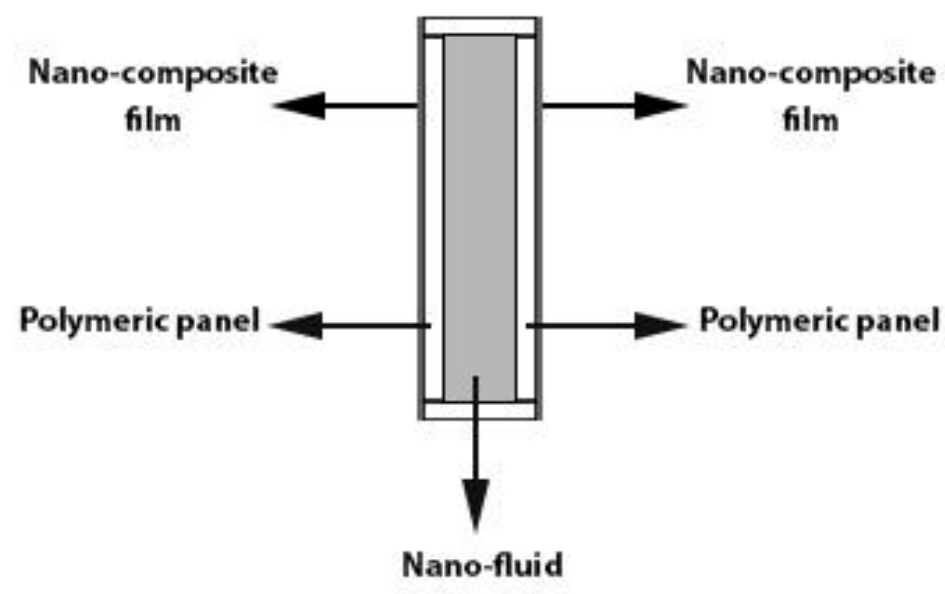

Fig. 2 Schematics of assembled sample

2.2.1.Polymeric panels

After analyzing different geometries, rotated cube appeared to be a better choice. In this pattern, the rotated cubes are considered as holes inside the plate. Fig. 3 shows the details of this design. Using this design will cause the light to refract successively, when the fluid is not inside the window. Consequently, the percentage of transmission is significantly reduced. In contrast, the presence of fluid increases the transparency considerably due to refraction index conformity between fluid and polymer. 

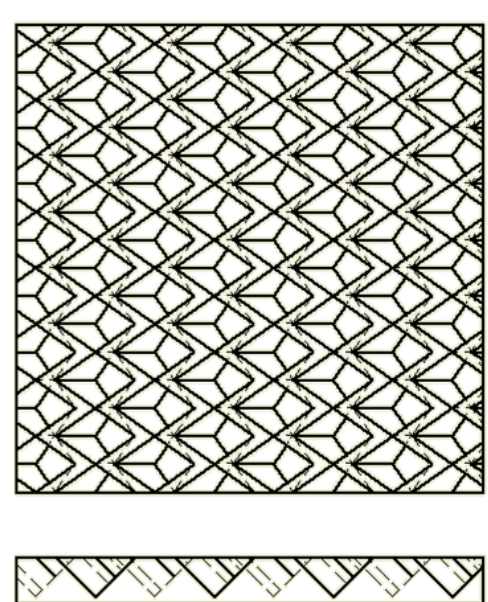

(a)

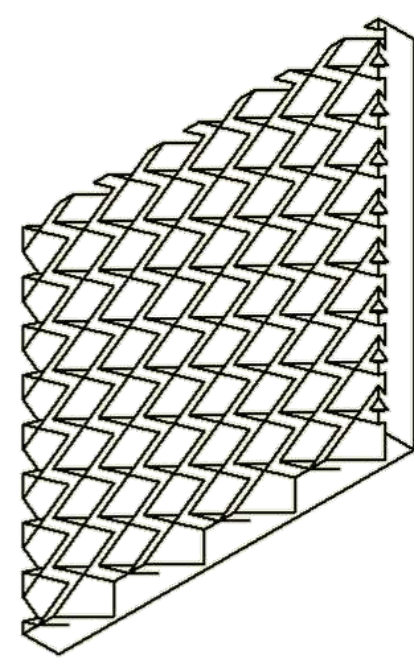

(b)

Fig. 3 Window panel with rotated cubes pattern; (a) Two-dimensional view; (b) Three-dimensional view.

Polymeric prototypes were firstly 3D-printed by Polyethylene (PE) (Fig. 4). Then resin mold was produced using polymeric prototype (Fig. 5). Finally, PMMA panels were fabricated by injecting polymer inside the strengthened resin mold.

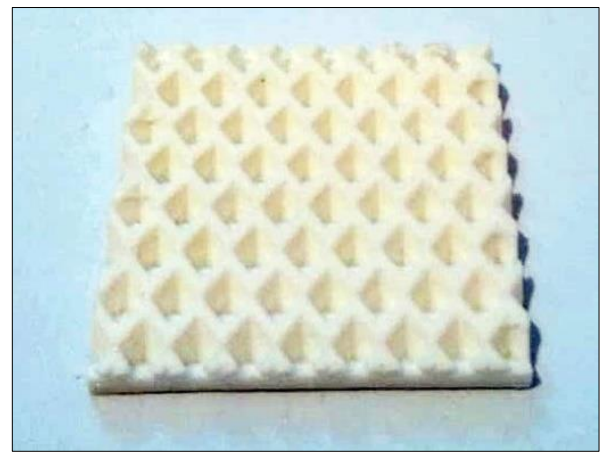

Fig. 4 3D printed polymeric prototype of panel.

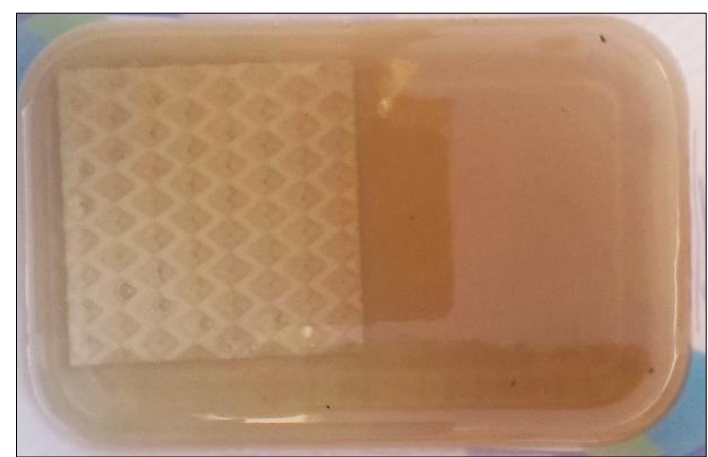

(a)

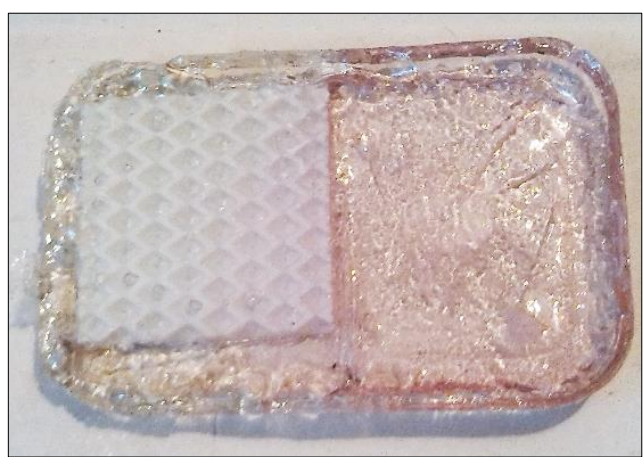

(b)

Fig. 5 Resin mold preparation; (a) Before curing; (b) After curing.

2.2.2.Nano-composite film 
The desired values of the percentage of nanoparticles are listed in Table 1. It should be noted that according to research, the maximum achievable concentration of nanoparticles in the polymer matrix is about $10 \mathrm{wt} \%$, which is due to the high surface energy and low mixability of nanoparticles.

Therefore, values lower than $10 \mathrm{wt} \%$ are considered here for the production of nanocomposites.

Table 1 Nano-particle percentage in nano-composite

\begin{tabular}{ccc}
\hline Sample & PMMA (gr) & ZnO (gr) \\
\hline $\mathrm{NCS}_{1}$ & 0.99 & 0.01 \\
$\mathrm{NCS}_{2}$ & 0.98 & 0.02 \\
$\mathrm{NCS}_{3}$ & 0.95 & 0.05 \\
\hline
\end{tabular}

To mix and dissolve the polymer in the solvent, a magnetic stirrer-heater with a maximum temperature of $120^{\circ} \mathrm{C}$ was used (Fig. 6). PMMA-fluid solution $\left(\frac{1 \mathrm{gr} \text { (PMMA) }}{50 \mathrm{ml} \text { (Fluid) }}\right)$, was obtained as a relatively thick white liquid. Since zinc oxide powder was purchased in the form of nanoparticles, there was no need for initial synthesis to prepare the oxide powder. Therefore, the powder was used directly. Then different amounts of zinc oxide nanoparticle powder were added to the solution. In the next step, the sample was mixed for $60 \mathrm{~min}$ at a temperature range of $60{ }^{\circ} \mathrm{C}$ to $65^{\circ} \mathrm{C}$, and a semiwhite product was obtained. At next step the gel state product was placed on a glass plate to prepare the film. Finally the produced film was placed at $80^{\circ} \mathrm{C}$ for $11 \mathrm{~min}$ to remove the solvent from the sample. The sample thickness was measured in different spots and the desired thickness was considered to be $30 \mu \mathrm{m}$.

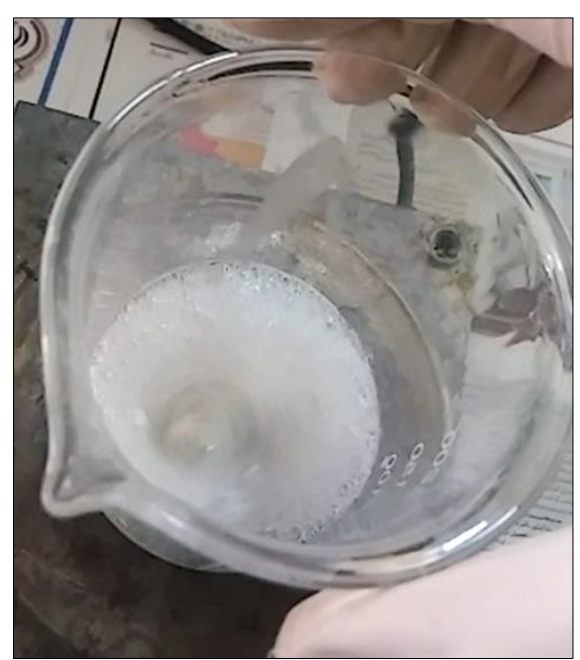


Fig. 6 Dissolving polymer in propanone (acetone).

2.2.3.Nano-fluid

To prepare the desired nanofluid, zinc oxide nanoparticles were added and mixed with concentrations of $0.1,0.5$, and $1 \mathrm{wt} \%$ according to the mass of the desired fluid (Table 2). The mixture was then placed on a magnetic stirrer before performing the ultrasonic process to ensure re-dispersion of nanoparticles in the base fluid.

Table 2 Nano-particle percentage in fluid.

\begin{tabular}{cc}
\hline Sample & ZnO (wt\%) \\
& \\
$\mathrm{NFS}_{1}$ & 0.1 \\
$\mathrm{NFS}_{2}$ & 0.5 \\
$\mathrm{NFS}_{3}$ & 1 \\
\hline
\end{tabular}

\subsubsection{Assembled product}

In order to simplify the production and assembly process of sample, the dimensions of the sample are considered to be currently $0.1 \times 0.1 \mathrm{~m}^{2}$. The final assembly was obtained by attaching the panels and installing holes required for fluid injection/drain (Fig. 7).

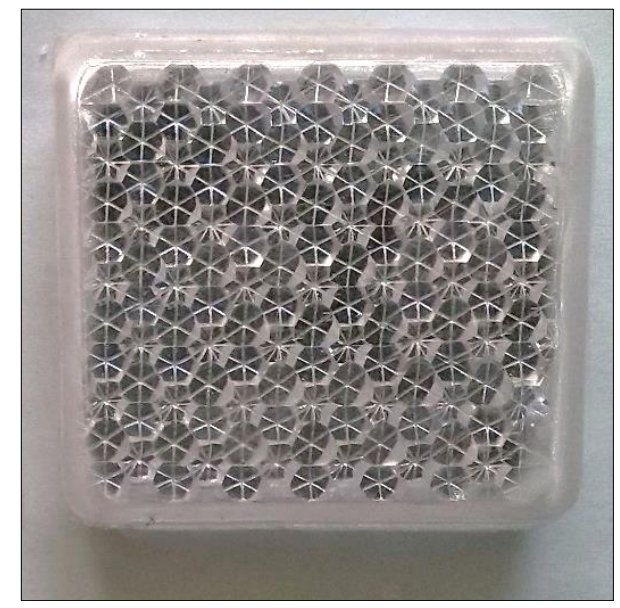

(a)

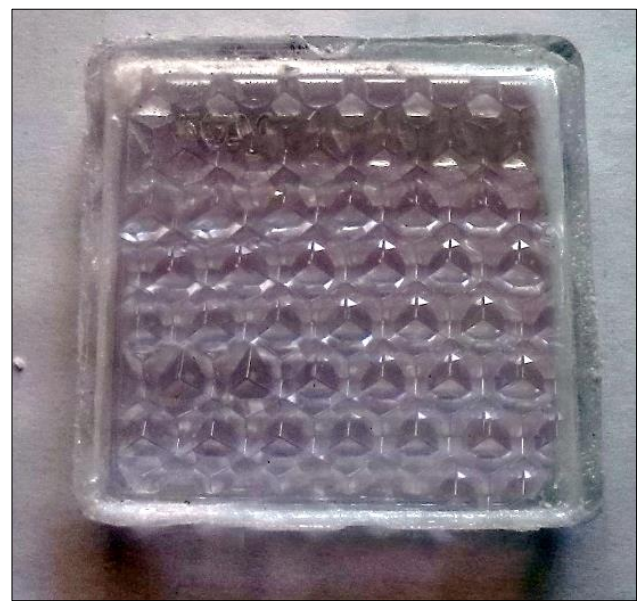

(b)

Fig. 7 The assembled product; (a) external view; (b) Internal view (Dsiassembled)/

\subsection{Tests}

Characterization tests have been performed in the field of physical, mechanical, thermal, structural and optical properties on product components. 


\subsubsection{Physical properties}

\subsubsection{C Contact angle test (ASTM D7490)}

Contact angle test was performed based on ASTM D7490 with the aim of achieving compatibility between fluid and solid materials used in the sample. To perform this test, the method of measuring the contact angle and surface tension with the help of droplets in the CA-ES10 device was used. Contact angle testing was performed for polymer sheets and nanocomposite films versus water, fluid, and nano-fluid with two replicates. The technical characteristics of this device are presented in Table 3, and the polymeric sample is shown in Fig. 8 .

Table 3 Technical specifications of contact angle measuring device CA-ES10

\begin{tabular}{lc}
\multicolumn{1}{c}{ Parameter } & Value \\
\hline Available range & $3-72 \frac{\mathrm{mN}}{\mathrm{m}}$ \\
Available contact angle range & $5^{\circ}-179^{\circ}$ \\
Number of automatic pumps & 1 \\
Number of background light & 1 \\
Number of camera positioner & 1 \\
\hline
\end{tabular}

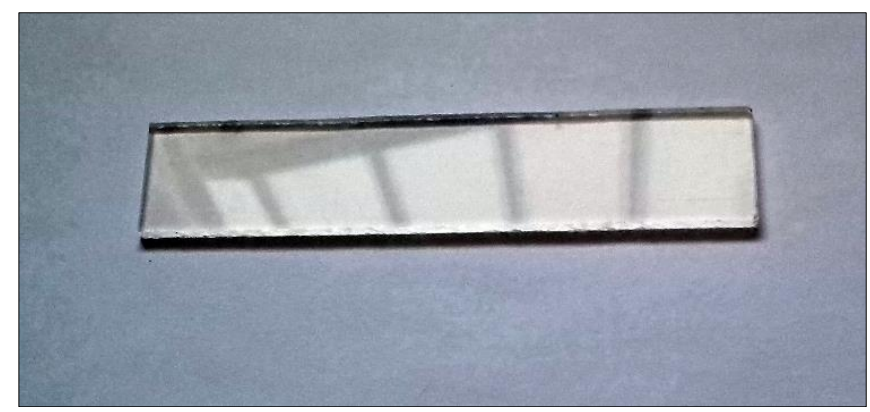

Fig. 8 PMMA samples for contact angle test.

2.3.2. Mechanical properties

\subsubsection{Tensile test (ASTM D638)}

Tensile test was performed for polymer panels with two replicates on the samples (Fig. 9). The TinusOlsen ST-100 was used to perform this test. 


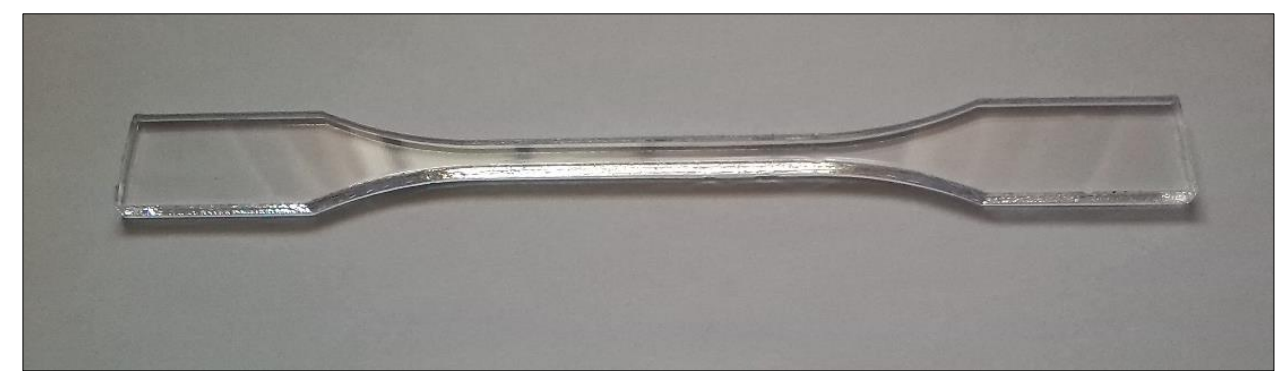

Fig. 9 PMMA samples for tensile test.

\subsubsection{2. $\quad$ Impact test (ASTM D4812)}

Impact test was performed for polymer panels with two replicates. PIT-501A device was used for this test.

\subsubsection{Flexure test (ASTM D790)}

Flexure test for polymer panels was performed twice with a strain rate of $2 \frac{\mathrm{mm}}{\mathrm{min}}$ on the samples (Fig. 10). The Tinus-Olsen ST-100 was used to perform this test.

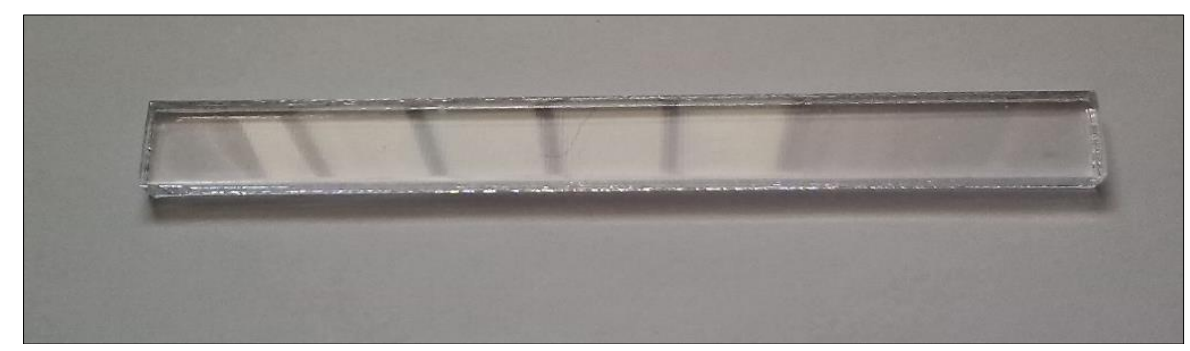

Fig. 10 PMMA samples for flexure test

2.3.3.Thermal properties

\subsubsection{DSC test (ASTM D3418)}

Since PMMA is a thermoplastic polymer, it was important to determine the glass transition temperature range $\left(T_{g}\right)$, melting temperature $\left(T_{m}\right)$ (process temperature range), and crystallization temperature using the DSC test to perform the fabrication process. This test has been done for polymer and nanocomposite. To perform DSC test, SA059 device with technical specifications in Table 4 has been used.

Table 4 Technical specifications of DSC test device SA059 


\begin{tabular}{lc}
\hline Temperature range & $-150^{\circ} \mathrm{C}-700^{\circ} \mathrm{C}$ \\
Temperature accuracy & $\pm 0.2 \mathrm{~K}$ \\
Temperature precision & $\pm 0.02 \mathrm{~K}$ \\
Heating rate & $0.02 . .300 \mathrm{~K} / \mathrm{min}$ \\
Cooling rate & $0.02 . .50 \mathrm{~K} / \mathrm{min}$ \\
Power resolution & $0.01 \mu \mathrm{W}$ \\
Measurement environment & $\mathrm{N}_{2}, \mathrm{O}_{2}, \mathrm{Air}$ \\
\hline
\end{tabular}

2.3.3.2. Heat conductivity test (ASTM D5930)

Heat conductivity coefficient of polymer and nanocomposite film has been measured to recognize the heat transfer rate of external and internal surfaces of the product. SDK TCC 001 (Fig. 11), with the technical specifications in Table 5 has been used to perform this test.

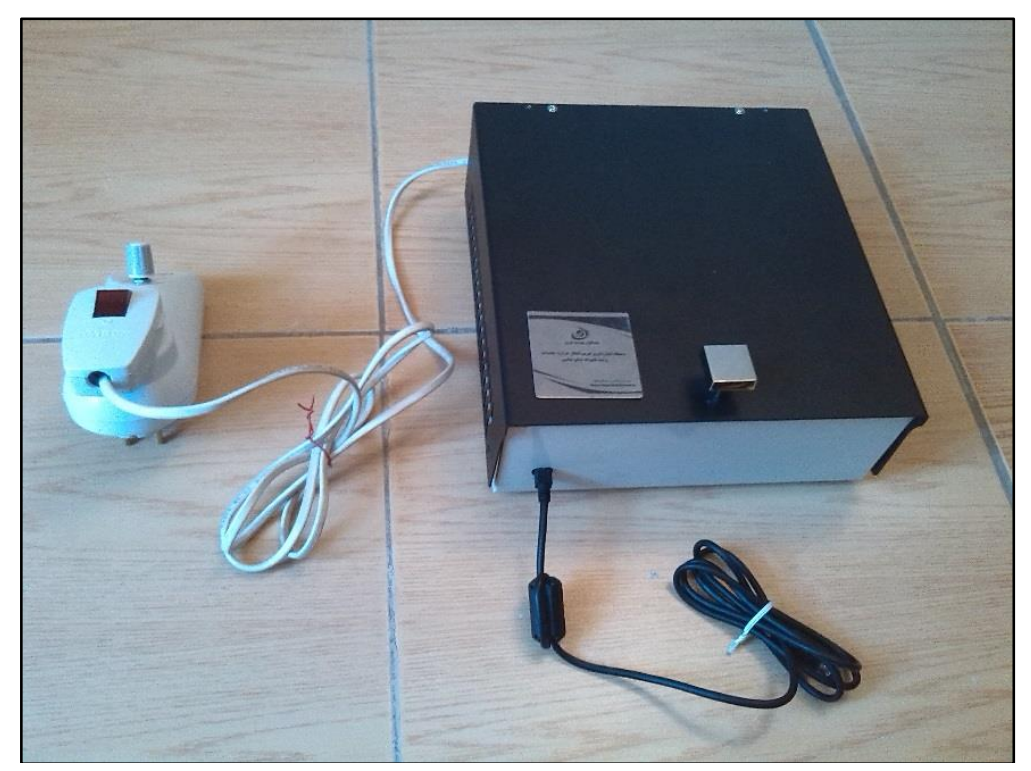

Fig. 11 SDK TCC 001 Heat transfer conductivity measuring device used in experiments (Fabricated by author).

Table 5 Technical specifications of SDK TCC 001 Heat transfer conductivity measuring device

Parameter

Temperature range

Temperature accuracy

Temperature precision

Input power
Value

$$
20^{\circ} \mathrm{C}-100^{\circ} \mathrm{C}
$$$$
\pm 1^{\circ} \mathrm{C}
$$$$
\pm 1^{\circ} \mathrm{C}
$$

$100 \mathrm{~W}$ 


\subsubsection{Optical properties}

\subsubsection{UV-VIS-NIR Spectroscopy (ASTM E1348)}

Spectrophotometric test was used to evaluate the light absorption and transmission of window elements using JASCO-V670 device with the technical specifications in Table 6. This test was performed for different subsets of components including simple polymer panels with nanocomposite films and nanofluid with two replications.

Table 6 Technical specifications of the spectrophotometry test device

\begin{tabular}{lc}
\multicolumn{1}{c}{ Parameter } & Value \\
\hline Spectral range & $190-2700 \mathrm{~nm}$ \\
Available test types & UV-Vis Transmission, UV-Vis \\
Cell type & Reflectance \\
\hline
\end{tabular}

\subsubsection{Structural characteristics}

\subsubsection{Light and electron microscopy (ASTM E2015)}

The nanocomposite and fluid structural characterizations were each performed separately to determine the existing structure. This was done for nanoparticles by X-ray diffraction based on ASTM D5357 by Bruker D8-Advance with the technical specifications in Table 7 with two replications. To perform this test $\mathrm{ZnO}$ nanoparticles were subjected to $\mathrm{X}$-ray scattering test with specifications of $40 \mathrm{kV}$ and $20 \mathrm{~mA}$. The crystal dimensions of $\mathrm{ZnO}$ particles were obtained using Equation Eq. (1) (Gopi, Kavitha, Ramya, \& Rajeswari, 2016):

$$
d=\frac{K \lambda}{\beta \cdot \cos \theta}
$$

Where $d$ is the crystal dimension, $K$ is the dimensionless shape factor with a value close to the unit value, $\lambda$ is the beam wavelength, $\theta$ is the radiation angle, and $\beta$ is the width of the half of the maximum value at the peak of the scatter. 
Table 7 Technical specifications of XRD test device (Bruker D8-Advance)

\begin{tabular}{lc}
\multicolumn{1}{c}{ Parameter } & Value \\
\hline Configurations & $\theta / \theta$ or $\theta / 2 \theta$ \\
Default measuring diameter & $500 \mathrm{~mm}$ and $560 \mathrm{~mm}$ \\
Angle range & $360^{\circ}$ \\
Maximum measurable range & $-110^{\circ}<2 \theta \leq 168^{\circ}$ \\
Angular resolution & $0.0001^{\circ}$ \\
Maximum angular speed & $20 \frac{\mathrm{deg}}{\mathrm{s}}$ \\
\hline
\end{tabular}

For nanocomposite film, the structural test was performed by scanning electron microscope based on ASTM E2015 using Philips XL30 with the technical specifications in Table 8 with two replications. Thus the morphology and chemical composition of nanocomposite films were examined with a $10 \mathrm{kV}$ SEM with low suction.

Table 8 Technical specifications of SEM test device (Philips XL30)

\begin{tabular}{lc}
\multicolumn{1}{c}{ Parameter } & Value \\
\hline Resolution & $2.0 \mathrm{~nm}$ \\
Available sample dimensions & X: $50 \mathrm{~mm}$, Y: $50 \mathrm{~mm}$, Z: $50 \mathrm{~mm}$ \\
Maximum storable image file size & 1404 x 968 pixels $-1.31 \mathrm{MB}$ \\
\hline
\end{tabular}

For nanofluid, dynamic light scattering (DLS) method was performed based on ASTM E2490 using NanoPartica SZ-100V2 device with technical specifications referred in Table 9 with two replications. Nano particle size analysis was performed in the desired solution with a laser beam with a wavelength of $632 \mathrm{~nm}$.

Table 9 Technical specifications of DLS test device (NanoPartica SZ-100V2)

Parameter Value

\begin{tabular}{lc}
\hline Available measuring size (Particle size) & $0.3-8 \mu \mathrm{m}$ \\
Available measuring size (Molecular weight) & $1000-2 \times 10^{7} \mathrm{Da}$ \\
Maximum allowable thickness of sample & $40 \mathrm{wt} \%$ \\
Measurement accuracy & $\pm 2 \% \times 100 \mathrm{~nm}$ \\
Measurement angles & $90^{\circ}$ and $173^{\circ}$ \\
Required sample volume & $12-1000 \mu \mathrm{m}$ \\
\hline
\end{tabular}

3. Results and discussion 


\subsection{Mechanical tests}

\subsubsection{Polymeric panels}

\subsubsection{Tensile test}

Tensile test results performed on polymer plates is demonstrated in Fig. 12. The average value obtained for different parameters is presented in Table 10 .

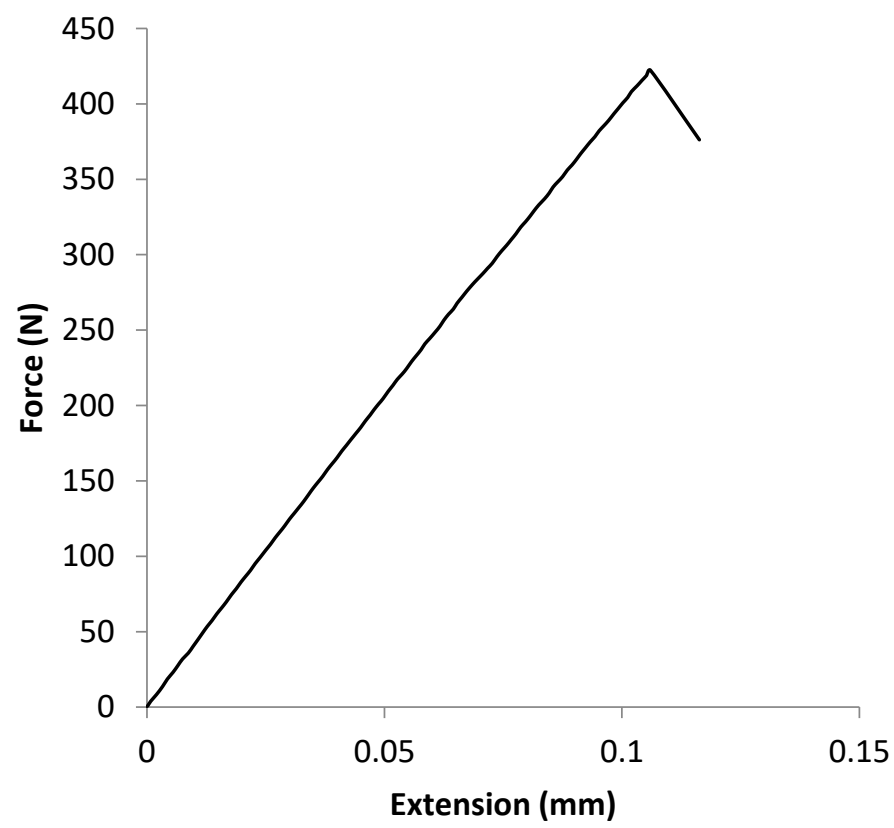

Fig. 12 Polymeric sample tensile test results.

Table 10 Important results of tensile test on polymeric samples

$\begin{array}{lll}\text { Parameter Symbol Value } & \text { S }\end{array}$

\begin{tabular}{lcc}
\hline Tensile strength & $S_{y}$ & $17.60 \mathrm{MPa}$ \\
Tensile elasticity modulus & $E$ & $8.5 \mathrm{GPa}$ \\
Elongation & $e_{f}$ & $0.21 \%$ \\
\hline
\end{tabular}

The tensile test results have been normal and acceptable according to the results obtained in Fig. 12.

\subsubsection{Impact test}

The impact test results performed on the polymer plates were measured. According to the obtained results, the average measured toughness value has been $15 \frac{\mathrm{J}}{\mathrm{m}^{2}}$. The results has been normal and acceptable. 


\subsubsection{Flexural test}

The results of the flexure test performed on the polymer plates is mentioned in Fig. 13. The average value obtained for different parameters is presented in Table 11.

Table 11 Important results of flexural test on polumeric samples

$$
\begin{array}{lll}
\text { Parameter Symbol Value } & \text { Sy }
\end{array}
$$

\begin{tabular}{lcc}
\hline Flexural strength & $S_{y b}$ & $-0.82 \mathrm{MPa}$ \\
Flexural elasticity modulus & $E_{b}$ & $0.019 \mathrm{GPa}$ \\
Flexural elongation & $e_{f b}$ & $-4.28 \%$ \\
\hline
\end{tabular}

Extension (mm)

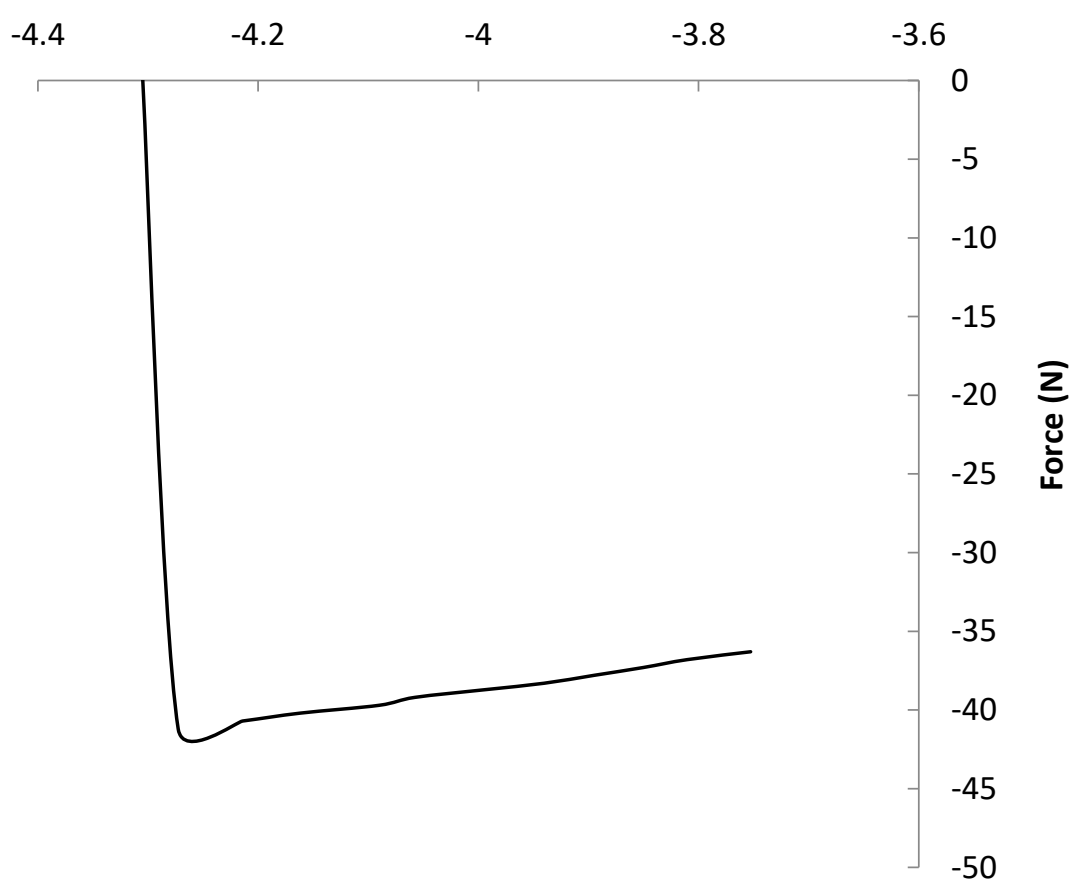

Fig. 13 Polymeric sample flexural test results.

According to the results obtained in Fig. 13 the results have been normal and acceptable.

3.2. Physical test

3.2.1. Contact angle 
The results of contact angle test between fluid and solid (polymer) are presented in Table 12. An example of the image presented in this test is depicted in Fig. 14.

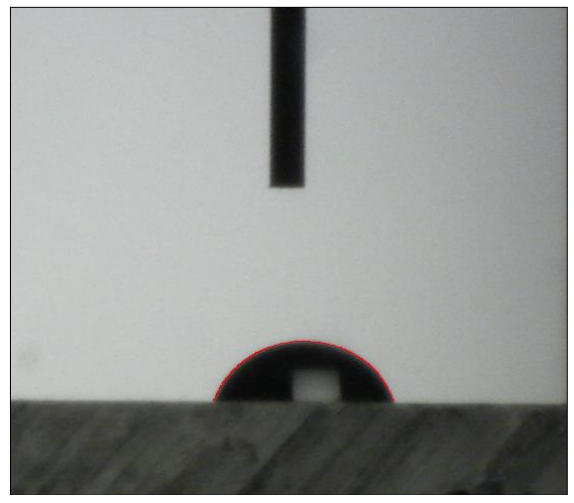

Fig. 14 Photograph of a contact angle test between polymeric sample and water.

Table 12 Contact angle test results.

\section{Sample}

Contact angle (Averagre value) $\left(^{\circ}\right)$

\begin{tabular}{ll}
\hline Polymeric panel - Water & 74 \\
Polymeric panel - Fluid & 76 \\
Polymeric panel - Nano-fluid & 78 \\
Nano-composte film - Water & 76 \\
Nano-composte film - Fluid & 79 \\
Nano-composte film - Nano-fluid & 81 \\
\hline
\end{tabular}

According to the results obtained in Table 12, the results related to polymeric panels and water has been normal according to other studies (Ma, Cao, Feng, Ma, \& Zou, 2007). The value has increased In the case of polymer and fluid. This is even more for panels and nanofluid which indicates higher fluid phobicity of the PMMA and nanofluids.

As the results show the contact angle for nanocomposite film and fluid has increased in all three cases indicating that the film is more fluid-phobic. The maximum value is obtained for nanocomposite film and nanofluid. Although fluid phobicity alone does not reflect the property of self-cleaning, the point here is that this property will be less effective if the surface is not exposed to environmental pollution. Because when the film is exposed to contamination, there is a possibility of non-fluid particles adhering to it, which will require surface washing due to its subtle fluid-philicity property. Therefore, the fluid-phobicity of the inner surfaces of the window will cause self-cleaning inside the window. 


\subsection{Structural test}

\subsubsection{Nanoparticles}

\subsubsection{XRD test}

XRD test results on nanoparticles in Fig. 15 mentioned.

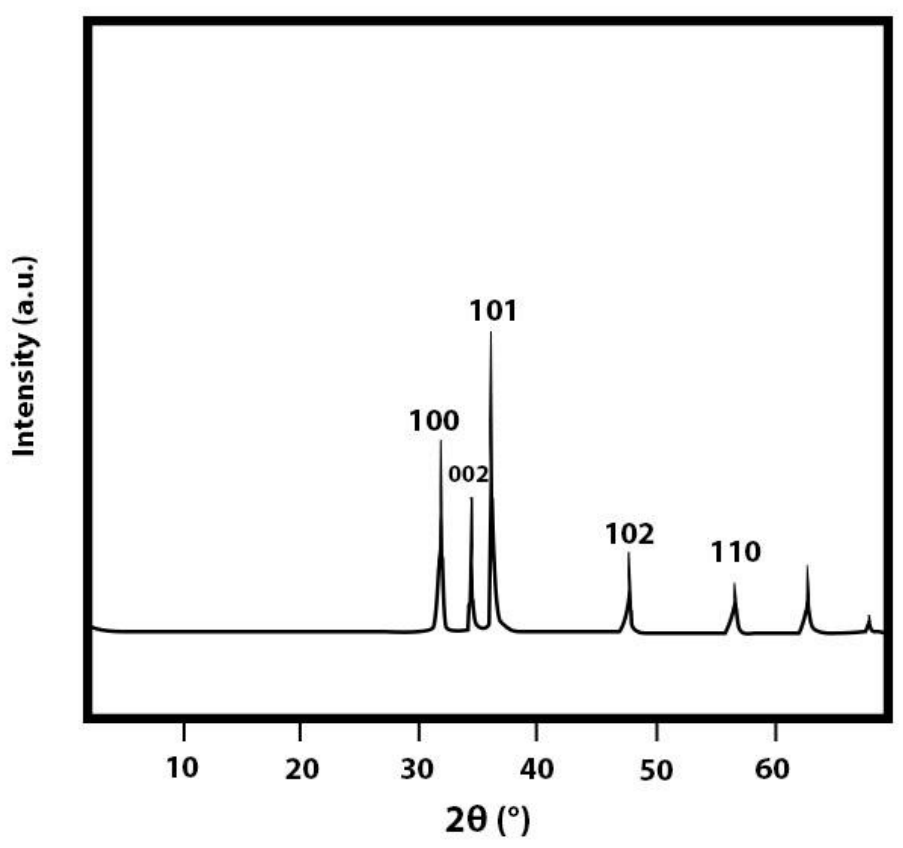

Fig. 15 XRD patterm obtained for $\mathrm{ZnO}$ nano-particles with Ethanol.

\subsubsection{SEM test}

A section of SEM test result on the nanocomposite is demonstrated in Fig. 16. The result shows the common granularity of zinc oxide nanoparticles in nanocomposite.

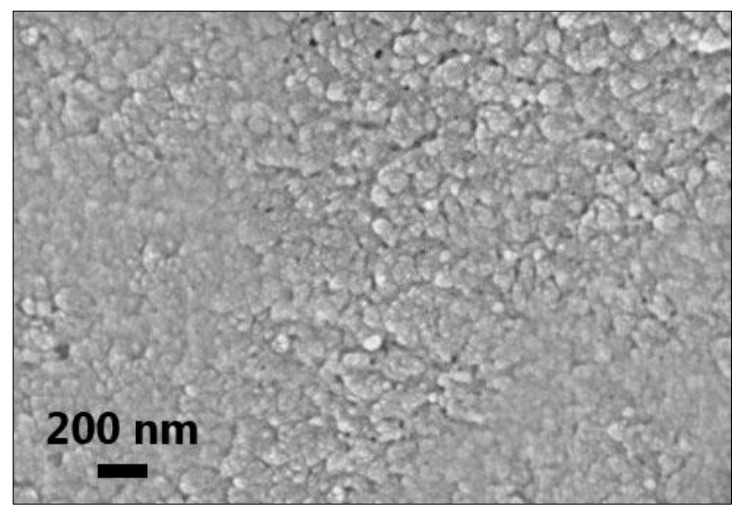

Fig. 16 SEM photo obtained from Nano-composite film. 
According to the results obtained in Fig. 15, zinc oxide particles size have been acceptable and it is within the standard range for nanocomposites and nanofluids. In addition, as seen in Fig. 16, the surface obtained from the nanocomposite film is in appropriate condition according to the results of similar studies (Hammani et al., 2018).

\subsubsection{Nanofluid}

\subsubsection{DLS test}

The results of DLS test on nanofluid in the range of $0-100 \mathrm{~nm}$ shows the acceptable dispersion of nanoparticles in the fluid. The results show that the particle dimensions have been between $3.5 \mathrm{~nm}$ and $12 \mathrm{~nm}$.

\subsection{Thermal test}

\subsubsection{DSC test}

The DSC test result is shown in Fig. 17 on pure polymer. The rest of PMMA results with different zinc oxide percentages are shown in Table 13.

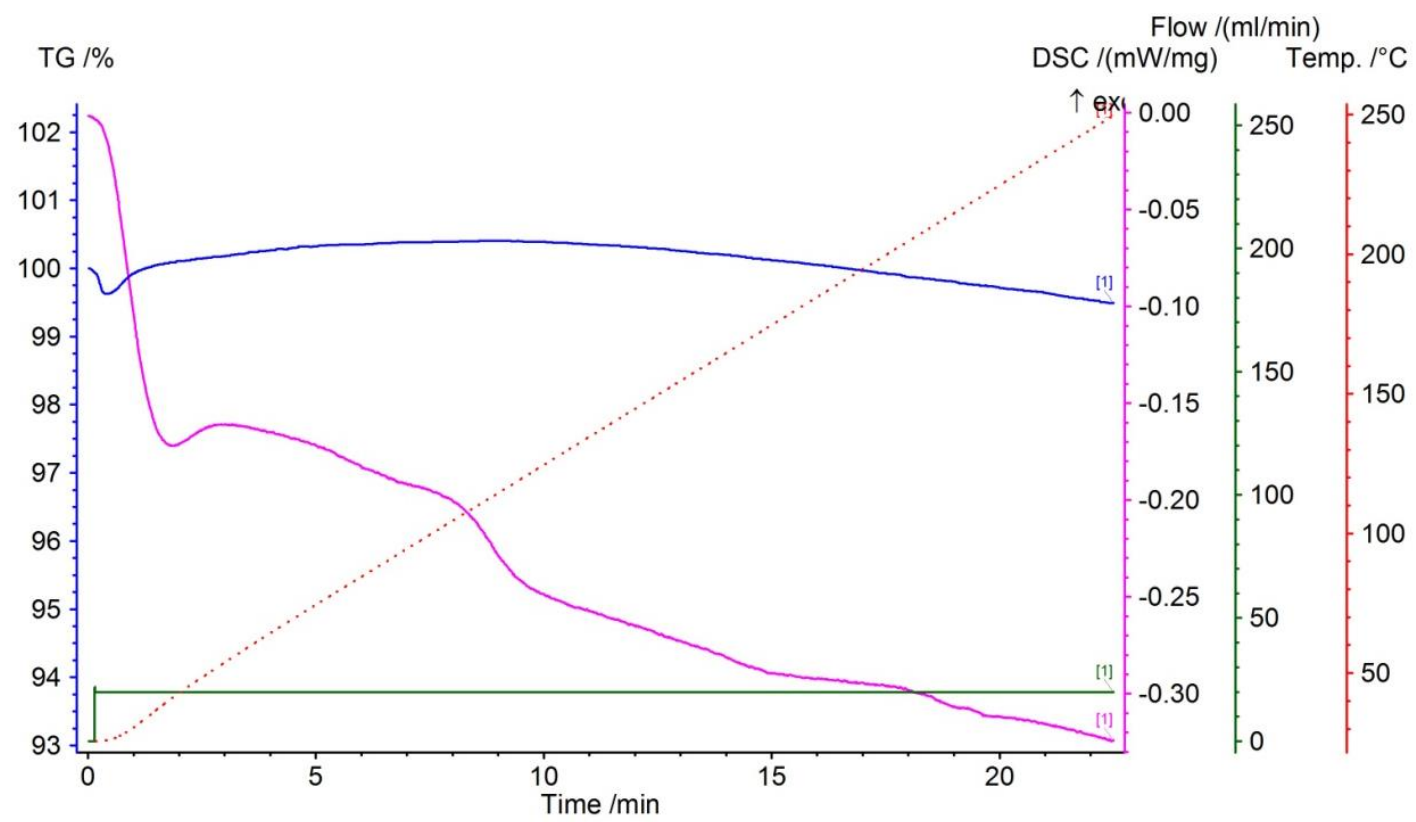

Fig. 17 DSC test result on PMMA.

As data show $T_{g}$ in nanocomposite films are higher than pure polymer, this value has increased with increasing percentage of $\mathrm{ZnO}$ nanoparticles. $T_{g}$ of pure polymer is about $90.5^{\circ} \mathrm{C}$. 
Table 13 DSC test results on nano-composite ( $\mathrm{ZnO}$ percentages refereed in Table 1)

\begin{tabular}{cc} 
Sample & $\boldsymbol{T}_{\boldsymbol{g}}\left({ }^{\circ} \mathbf{C}\right)$ \\
\hline $\mathrm{NCS}_{1}$ & 90.5 \\
$\mathrm{NCS}_{2}$ & 94.6 \\
$\mathrm{NCS}_{3}$ & 97.8 \\
\hline
\end{tabular}

According to the results obtained in Fig. 17 and Table 13 the range of vitrification and melting of the polymer is suitable for its manufacture. An important point to be seen in these results is that $T_{g}$ has increased with increasing the percentage of $\mathrm{ZnO}$, which could be due to the lack of complete solubility of the polymer in the solvent and ruduction in molecular weight distribution. This is due to the direct relationship of $T_{g}$ value to the mobility of the polymer chain (Kim et al., 2012). Although $T_{g}$ does not necessarily affect the performance of the window, knowing its thermal characteristics can ensure a safe temperature range for its working conditions.

\subsubsection{Thermal conductivity test}

The results of the thermal conductivity coefficient test are listed in Table 14.

Table 14 Thermal conductivity coefficient test results

\begin{tabular}{lc}
\multicolumn{1}{c}{ Sample } & $\begin{array}{c}\text { Thermal conductivity coefficient } \\
\text { (Average) }\left(\frac{\mathbf{w}}{\mathbf{m} \cdot \mathbf{K}}\right)\end{array}$ \\
\hline Polymeric panels & 0.193 \\
Nano-composite film $\left(\mathrm{NCS}_{1}\right)^{*}$ & 0.215 \\
Nano-composite film $\left(\mathrm{NCS}_{2}\right)^{*}$ & 0.220 \\
Nano-composite film $\left(\mathrm{NCS}_{3}\right)^{*}$ & 0.291 \\
\hline${ }^{*}$ Refer to Table 1
\end{tabular}

The thermal conductivity coefficient has increased slightly with increasing the percentage of zinc oxide according to the results obtained in Table 14. Although this parameter does not have considerable influence on the desired performance of the window, it will be considered in terms of heat loss, or the input of unwanted heat from outside. In general, it can be said that the panel of the window play a more insulating role than conductive.

\subsection{Optical test}


Fig. 18 and Table 15 show the results of the UV-Vis test for polymers, nanocomposites, and nanofluids in visible and ultraviolet range in the room temperature. The results include plain and patterned polymeric panels, as well as windows containing fluid with different percentages of $\mathrm{ZnO}$ nanoparticles are shown in Table 15. According to the results, the variation in light transmittance for the opaque and transparent state is between $45 \%$ and $80 \%$. The opaque state occurs when the windows does not include the fluid and the transparent state occurs when complete set is used.

Table 15 Light transmision test results.

\begin{tabular}{|c|c|}
\hline Sample & $\begin{array}{l}\text { Transmission percentage } \\
\text { (Average) }(\lambda=500 \mathrm{~nm})\end{array}$ \\
\hline Simple polymeric panels & 87 \\
\hline Patterned polymeric panels & 45 \\
\hline Simple polymeric panels with & \\
\hline Nano-composite film $\left(\mathrm{NCS}_{3}\right)^{*}$ & 82 \\
\hline $\begin{array}{l}\text { Simple polymeric panels with } \\
\text { Nano-fluid }\left(\mathrm{NFS}_{3}\right)^{* *}\end{array}$ & 85 \\
\hline $\begin{array}{c}\text { Assembled window }\left(\mathrm{NCS}_{3}{ }^{*} \text { and }\right. \\
\left.\mathrm{NFS}_{3}{ }^{* *}\right)\end{array}$ & 80 \\
\hline $\begin{array}{l}\text { Refer to Table } 1 \\
\text { Refer to Table } 2 \\
\end{array}$ & \\
\hline
\end{tabular}

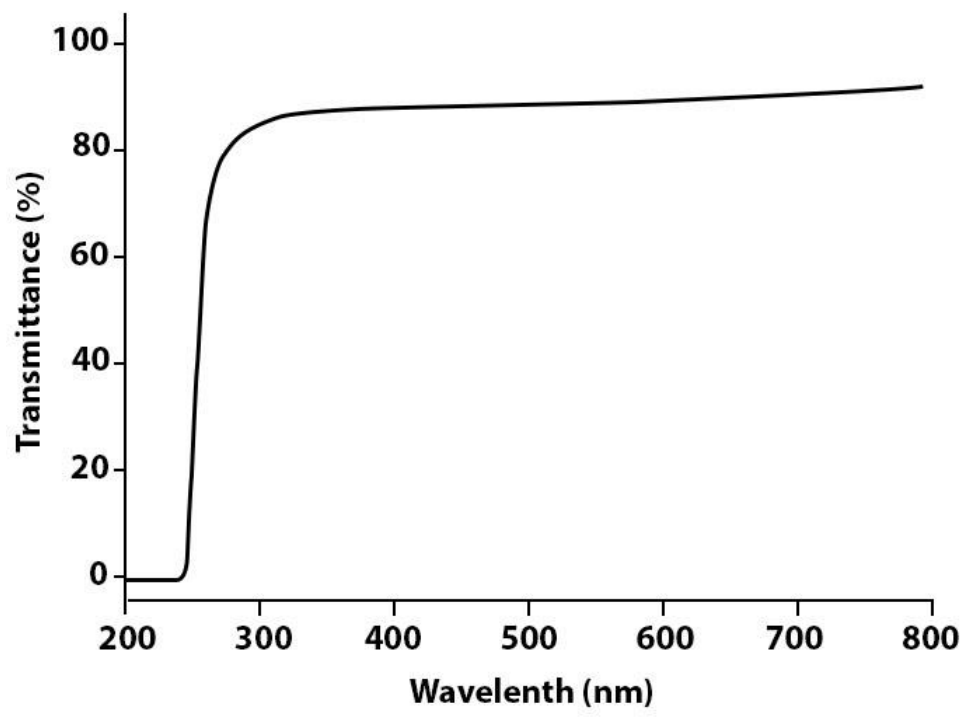

Fig. $18 \mathrm{UV}-$ Vis transmission curve, obtained for simple polymeric panels.

It should be noted that one of the features of smart glass is the time required to switch between the states. According to previous studies, this period is relatively time consuming for thermochromic, electrochromic, and gas chromic glasses due to the chemical processes required to change their state. 
This is also the case for other smart glasses. Glasses containing hydrogels, for example, take about 40 minutes to change state due to rising and falling temperatures (Gyenes, Szilágyi, Lohonyai, \& Zrínyi, 2003). The more advanced version of this window (containing microgels) has just reduced this time to 4 minutes (M. Wang et al., 2014). In glasses containing hydroxypropyl methyl cellulose, the time required to change state during the temperature reduction process is about 6 minutes (Kiruthika \& Kulkarni, 2017).

Although some efforts are seen in previous studies to reduce the switching time, must of them operate during a period longer than 1 or 2 minutes, while this period has reduced to a duration as short as 1 minute due to harnessing injection/drain mechanism in the proposed window. As mentioned previously, the mechanism operates in such a way that the presence or absence of fluid (nanofluid) inside the window and the matching of the refractive index between the fluid (nanofluid) and the panels, respectively, make the window transparent or opaque. However, it should be noted that the area of the window and the inlet-outlet flow of the fluid will also affect this period of time.

\subsection{Window performance}

After making the sample, temperature variations during the daylong for a testing chamber were compared in constant climatic conditions. The qualitative values of this analysis are shown in Table 16.

Table 16 Qualitative temperature variations during 12:00 to 13:00, while using proposed windows in normal and switched states.

$\begin{array}{cccc}\text { Qualitative } & \begin{array}{c}\text { Qualitative Internal } \\ \text { temperature } \\ \text { (Experimental) }\left({ }^{\circ} \mathrm{C}\right)\end{array} & \begin{array}{c}\text { Qualitative Internal } \\ \text { temperature } \\ \text { (Simulaiton) }\left({ }^{\circ} \mathbf{C}\right)\end{array} & \text { Glass state } \\ \text { External } & & & \end{array}$

\section{temperature}

$\left({ }^{\circ} \mathrm{C}\right)$

\begin{tabular}{lccc}
\hline High & High & High & High transparency \\
High & Medium & Medium & Low transparency \\
Low & Medium & Medium & High transparency \\
Low & Low & Low & Low transparency \\
\hline
\end{tabular}


As seen in Table 16 the temperature inside the chamber, is relatively favorable regarding the outside temperature by a suitable adjustment of the window state, and appropriate passage of sunlight. It should be noted that in order to achieve temperature stability, this experiment was performed within one hour. This way, the amount of energy savings for heating and cooling can be determined approximately according to the cost.

In overall, In comparison to other switchable windows, the versatile and efficient design proposed here has provided temperature independent system which is stimulated by small input power, requiring less energy consumption and just a drain/injection process to provide a reversible optical process.

\section{Conclusion}

The main benefits of using smart windows are reducing energy consumption and improving the building automation. The use of this technology is more necessary in summer, when energy consumption peaks for cooling systems as well as winter when these glasses play an effective role in reducing energy consumption by passing a high percentage of sunlight into the building since the sunlight is less intense due to the angles of the sunlight with the ground.

Although the technology of most smart glasses has had a positive impact on energy management, the significant cost of making these glasses is a major obstacle. Current smart windows which are switched by changes in the intensity of sunlight, are not only cost-effective to produce, but also do not work well in the long run. In addition, toxic substances are usually used in the process of making these types of windows, which can pose significant risks to nature and human health.

The proposed smart window offers a cheaper and more cost-effective idea for making these types of windows. In this window, the mentioned problems have been considerably resolved to an acceptable extent by using nontoxic materials and simple switching mechanism while having a stable performance in the long run. In addition, the time period for switching between the states is relatively short, while its fabrication cost is reasonable compared to similar types. The major advantages of this product can be summarized as follows: 
- The efficiency of the proposed window compared to the other available types such as electrochromic and low emission windows has been considerable in terms of energy consumption as expected. Light transmission in both states (opaque and transparent) for the proposed window causes to reduce heating and cooling costs compared to other smart windows. In fact, a higher percentage of sunlight passing in cold weather and a lower percentage of sunlight passing in hot weather is a clear proof for this.

- The selection of PMMA and proposed manufacturing method has reduced the complexity and the cost of fabricating a smart window as predicted. Although the cost used materials are acceptable, manufacturing costs can be reduced even more by using a turbid fluid. It can be adapted to the simple switching mechanism in reverse mode (Opaque when the fluid is injected, and transparent when the fluid is drained), making the design more simple and inexpensive. This way even the issue of refractive index compliance is no more a considered parameter, while the only issue will be self-cleaning. Therefore, the use of nanocomposite film is still inevitable. This mechanism require more research in the next studies.

- The proposed smart window has had a higher percentage of transparency than the existing products as predicted due to the matching properties of the polymer and nanofluid used here. It has been concluded that the light transmittance range for both opaque and transparent conditions is comparable to other smart windows according to the results obtained in Table 15.

- The research method has shown that the switching time is reduced compared to the existing smart windows. According to the other studies, the minimum time required to switch between states is about 4 minutes, while in the proposed window, this time is reduced to less than 1 minute, due to the simple injection/drain mechanism however the area of the window and the flow rate are two important controlling factors.

\section{Ethics declarations}

The research was funded by Iran National Science Foundation (INSF). 


\section{Conflict of Interests/Competing interests}

The authors declare no conflict of interests.

Availability of data and material (Not applicable)

Code availability (Not applicable)

\section{Authors' contributions}

All authors contributed to the study conception and design. Material preparation, data collection and analysis were performed by Mehdi Jafari Vardanjani and Mehdi Karevan. The first draft of the manuscript was written by Mehdi Jafari Vardanjani and all authors commented on previous versions of the manuscript. All authors read and approved the final manuscript.

\section{Ethics approval}

The research conducted in this work did not involve human participants or animals.

\section{Consent to participate}

All authors have read and consented to the final version of the manuscript.

\section{Consent for publication}

All authors have consented to the publishing of the manuscript.

\section{References}

Allen, K., Connelly, K., Rutherford, P., \& Wu, Y. (2017). Smart windows-Dynamic control of building energy performance. Energy and Buildings, 139, 535-546. doi:https://doi.org/10.1016/j.enbuild.2016.12.093

Baetens, R., Jelle, B. P., \& Gustavsen, A. (2010). Properties, requirements and possibilities of smart windows for dynamic daylight and solar energy control in buildings: A state-of-the-art review. Solar Energy Materials and Solar Cells, 94(2), 87-105. doi:https://doi.org/10.1016/j.solmat.2009.08.021

Cao, S., Zhang, S., Zhang, T., Yao, Q., \& Lee, J. Y. A Visible Light-Near-Infrared Dual-Band Smart Window with Internal Energy Storage. Joule. doi:10.1016/j.joule.2018.12.010 
Chen, Z., Cao, C., Chen, S., Luo, H., \& Gao, Y. (2014). Crystallised mesoporous TiO2(A)$\mathrm{VO} 2(\mathrm{M} / \mathrm{R})$ nanocomposite films with self-cleaning and excellent thermochromic properties. Journal of Materials Chemistry A, 2(30), 11874-11884. doi:10.1039/C4TA01585A

Dai Prè, M., Martucci, A., Martin, D. J., Lavina, S., \& Di Noto, V. (2015). Structural features, properties, and relaxations of PMMA-ZnO nanocomposite. Journal of Materials Science, 50(5), 2218-2228. doi:10.1007/s10853-014-8784-0

Demir, M. M., Koynov, K., Akbey, Ü., Bubeck, C., Park, I., Lieberwirth, I., \& Wegner, G. (2007). Optical Properties of Composites of PMMA and Surface-Modified Zincite Nanoparticles. Macromolecules, 40(4), 1089-1100. doi:10.1021/ma062184t

Feng, W., Zou, L., Gao, G., Wu, G., Shen, J., \& Li, W. (2016). Gasochromic smart window: optical and thermal properties, energy simulation and feasibility analysis. Solar Energy Materials and Solar Cells, 144, 316-323. doi:https://doi.org/10.1016/j.solmat.2015.09.029

Gopi, D., Kavitha, L., Ramya, S., \& Rajeswari, D. (2016). Chapter 15 - Chemical and green routes for the synthesis of multifunctional pure and substituted nanohydroxyapatite for biomedical applications. In A. M. Grumezescu (Ed.), Engineering of Nanobiomaterials (pp. 485-521): William Andrew Publishing.

Gyenes, T., Szilágyi, A., Lohonyai, T., \& Zrínyi, M. (2003). Electrically adjustable thermotropic windows based on polymer gels. Polymers for Advanced Technologies, 14(11-12), 757-762. doi:10.1002/pat.391

Hammani, S., Barhoum, A., \& Bechelany, M. (2018). Fabrication of PMMA/ZnO nanocomposite: effect of high nanoparticles loading on the optical and thermal properties. Journal of Materials Science, 53(3), 1911-1921. doi:10.1007/s10853-017-1654-9

Hoffmann, S., Lee, E. S., \& Clavero, C. (2014). Examination of the technical potential of nearinfrared switching thermochromic windows for commercial building applications. Solar Energy Materials and Solar Cells, 123, 65-80. doi:https://doi.org/10.1016/j.solmat.2013.12.017 
Hu, K., Blair, A. D., Piechota, E. J., Schauer, P. A., Sampaio, R. N., Parlane, F. G. L., . . Berlinguette, C. P. (2016). Kinetic pathway for interfacial electron transfer from a semiconductor to a molecule. Nature Chemistry, 8(9), 853-859. doi:10.1038/nchem.2549

Javad, K., \& Navid, G. (2019). Thermal comfort investigation of stratified indoor environment in displacement ventilation: Climate-adaptive building with smart windows. Sustainable Cities and Society, 46, 101354. doi:https://doi.org/10.1016/j.scs.2018.11.029

Kim, D., Jeon, K., Lee, Y., Seo, J., Seo, K., Han, H., \& Khan, S. (2012). Preparation and characterization of UV-cured polyurethane acrylate/ $\mathrm{ZnO}$ nanocomposite films based on surface modified ZnO. Progress in Organic Coatings, 74(3), 435-442. doi:10.1016/j.porgcoat.2012.01.007

Kiruthika, S., \& Kulkarni, G. U. (2017). Energy efficient hydrogel based smart windows with low cost transparent conducting electrodes. Solar Energy Materials and Solar Cells, 163, 231236. doi:https://doi.org/10.1016/j.solmat.2017.01.039

Li, X.-H., Liu, C., Feng, S.-P., \& Fang, N. X. (2019). Broadband Light Management with Thermochromic Hydrogel Microparticles for Smart Windows. Joule, 3(1), 290-302. doi:https://doi.org/10.1016/j.joule.2018.10.019

Ma, Y., Cao, X., Feng, X., Ma, Y., \& Zou, H. (2007). Fabrication of super-hydrophobic film from PMMA with intrinsic water contact angle below $90^{\circ}$. Polymer, 48(26), 7455-7460. doi:https://doi.org/10.1016/j.polymer.2007.10.038

Piccolo, A., \& Simone, F. (2015). Performance requirements for electrochromic smart window. Journal of Building Engineering, 3, 94-103. doi:https://doi.org/10.1016/j.jobe.2015.07.002

Sabry, M., Eames, P. C., Singh, H., \& Wu, Y. (2014). Smart windows: Thermal modelling and evaluation. Solar Energy, 103, 200-209. doi:https://doi.org/10.1016/j.solener.2014.02.016

Sala, R. L., Gonçalves, R. H., Camargo, E. R., \& Leite, E. R. (2018). Thermosensitive poly(Nvinylcaprolactam) as a transmission light regulator in smart windows. Solar Energy Materials and Solar Cells, 186, 266-272. doi:https://doi.org/10.1016/j.solmat.2018.06.037 
Sun, D., Miyatake, N., \& Sue, H.-J. (2007). Transparent PMMA/ZnO nanocomposite films based on colloidal ZnO quantum dots. Nanotechnology, 18, 215606. doi:10.1088/0957$4484 / 18 / 21 / 215606$

Wang, J., Zhang, L., Yu, L., Jiao, Z., Xie, H., Lou, X. W. D., \& Sun, X. W. (2014). A bi-functional device for self-powered electrochromic window and self-rechargeable transparent battery applications. Nature communications, 5(1), 1-7.

Wang, M., Gao, Y., Cao, C., Chen, K., Wen, Y., Fang, D., . . Guo, X. (2014). Binary Solvent Colloids of Thermosensitive Poly(N-isopropylacrylamide) Microgel for Smart Windows. Industrial \& Engineering Chemistry Research, 53(48), 18462-18472. doi:10.1021/ie502828b

Warwick, M. E. A., Ridley, I., \& Binions, R. (2014). The effect of transition gradient in thermochromic glazing systems. Energy and Buildings, 77, 80-90. doi:https://doi.org/10.1016/j.enbuild.2014.03.044

Wu, C.-C., Liou, J.-C., \& Diao, C.-C. (2015). Self-powered smart window controlled by a high opencircuit voltage InGaN/GaN multiple quantum well solar cell. Chemical Communications, 51(63), 12625-12628. doi:10.1039/C5CC04031K

Wu, L. Y. L., Zhao, Q., Huang, H., \& Lim, R. J. (2017). Sol-gel based photochromic coating for solar responsive smart window. Surface and Coatings Technology, 320, 601-607. doi:https://doi.org/10.1016/j.surfcoat.2016.10.074

Zettl, M., Mayer, O., Klampaftis, E., \& Richards, B. S. (2017). Investigation of Host Polymers for Luminescent Solar Concentrators. Energy Technology, 5(7), 1037-1044. doi:10.1002/ente.201600498 
Figures

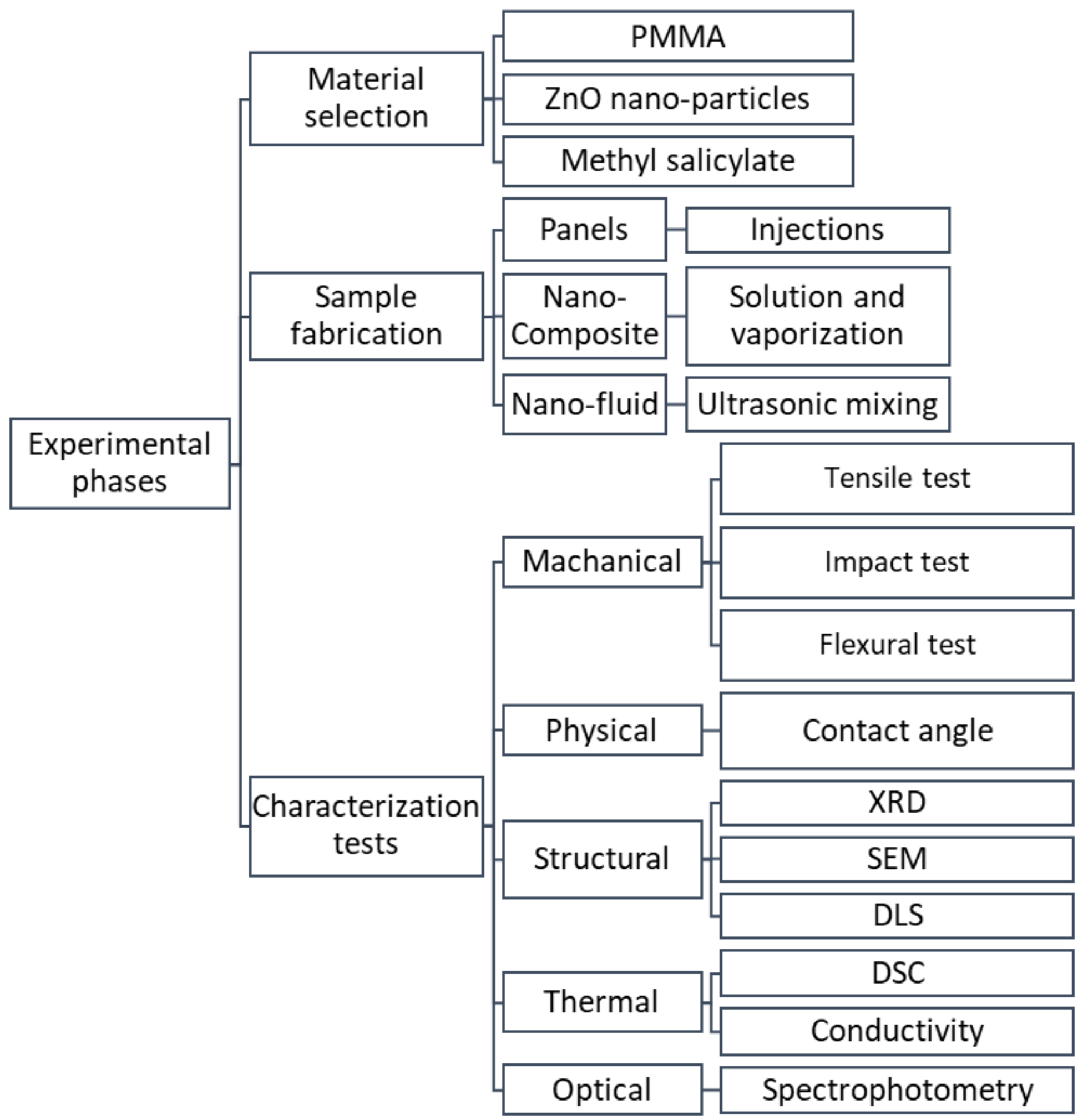

Figure 1

Experimental steps 


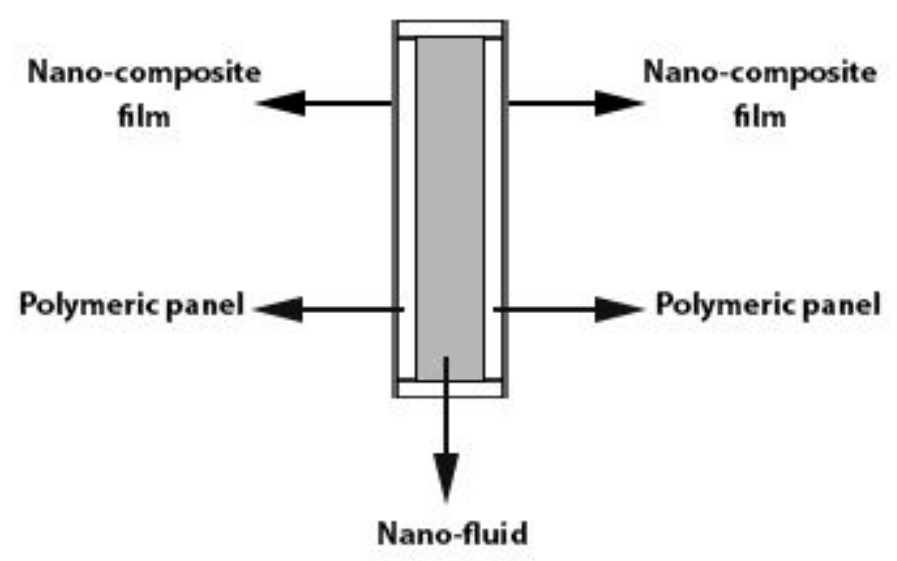

Figure 2

Schematics of assembled sample
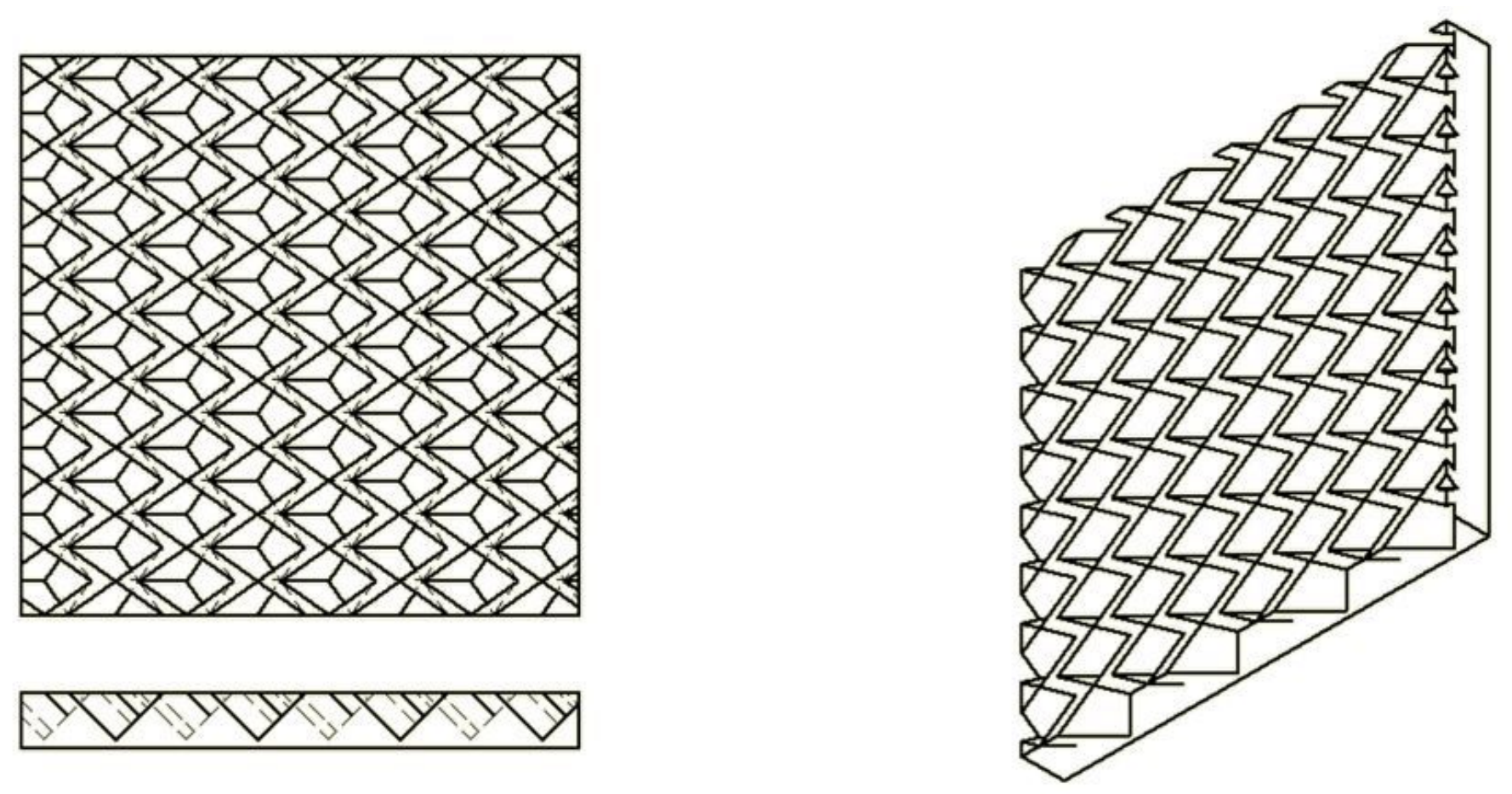

(a)

(b)

Figure 3

Window panel with rotated cubes pattern; (a) Two-dimensional view; (b) Three-dimensional view. 


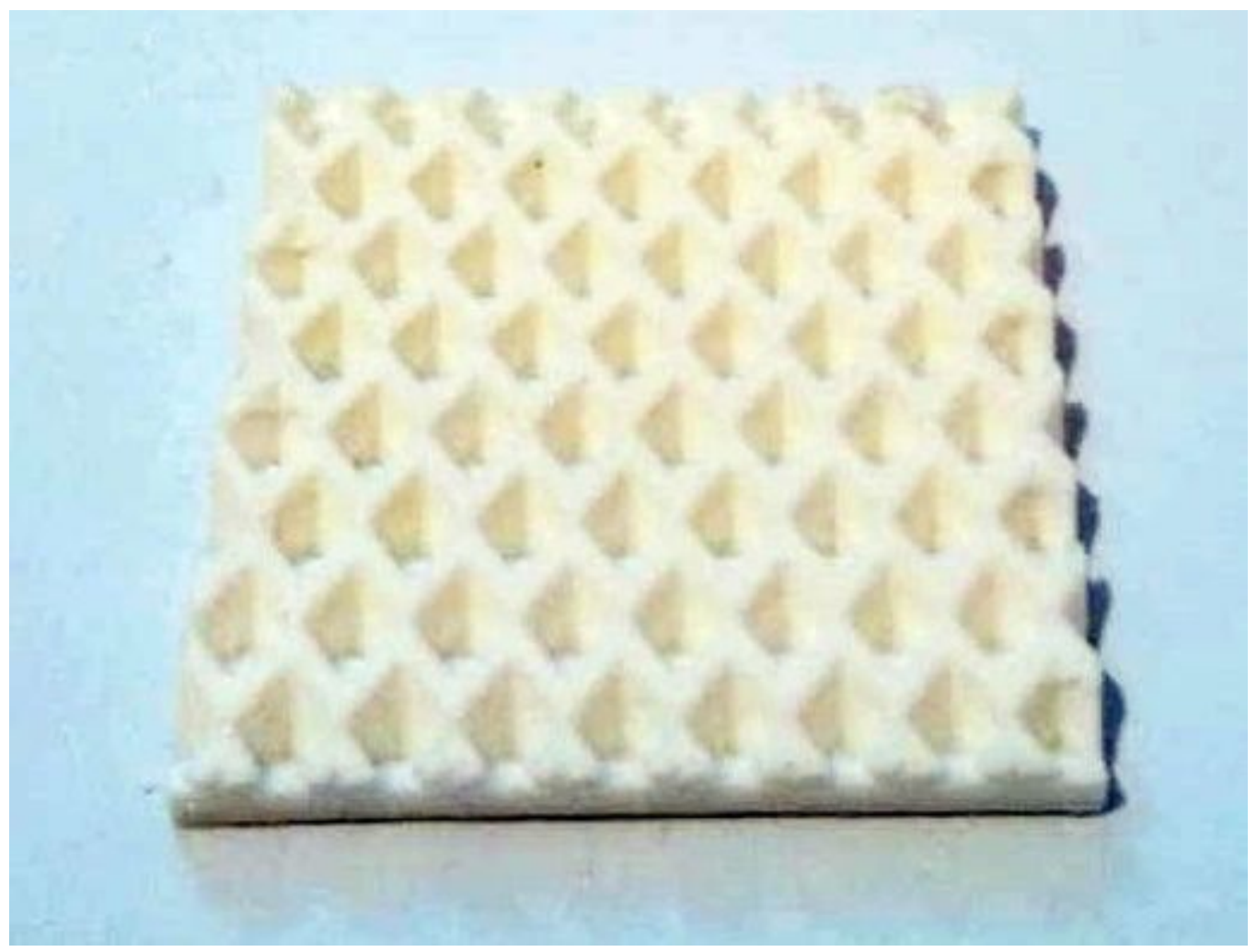

Figure 4

3D printed polymeric prototype of panel.

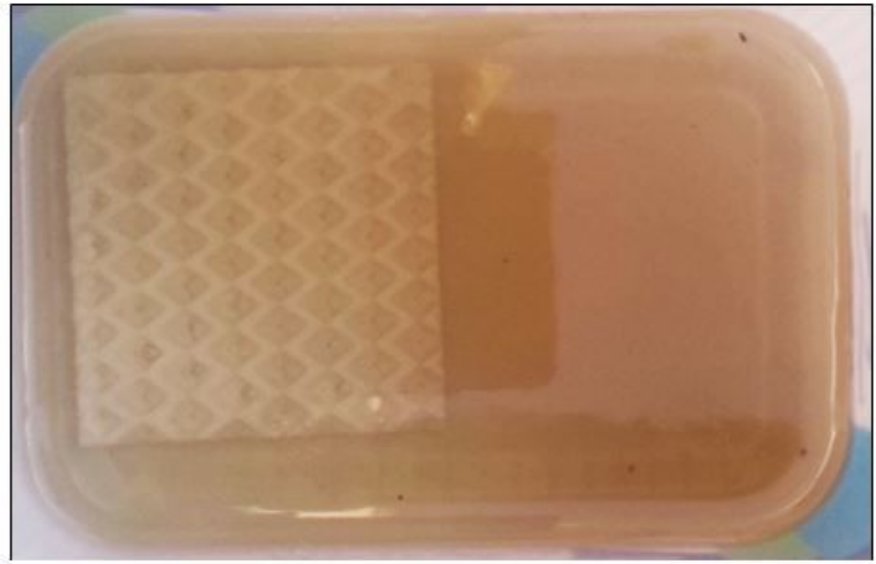

(a)

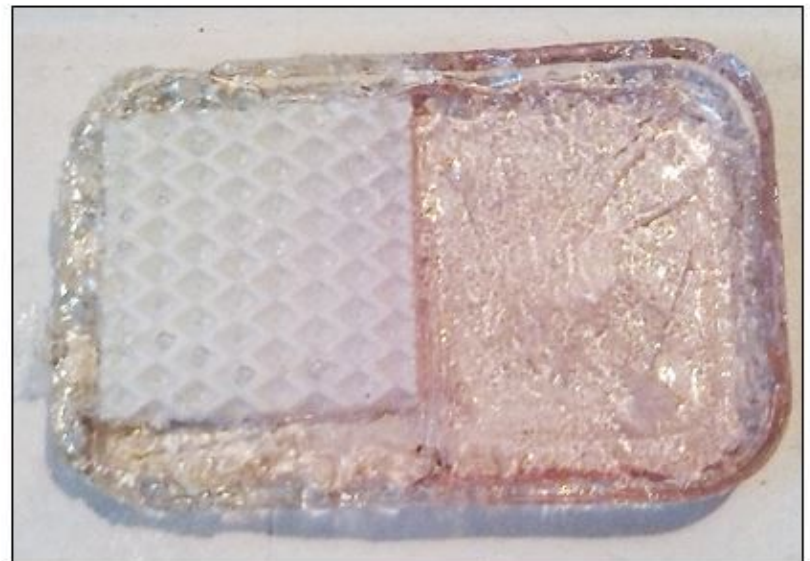

(b)

\section{Figure 5}

Resin mold preparation; (a) Before curing; (b) After curing. 


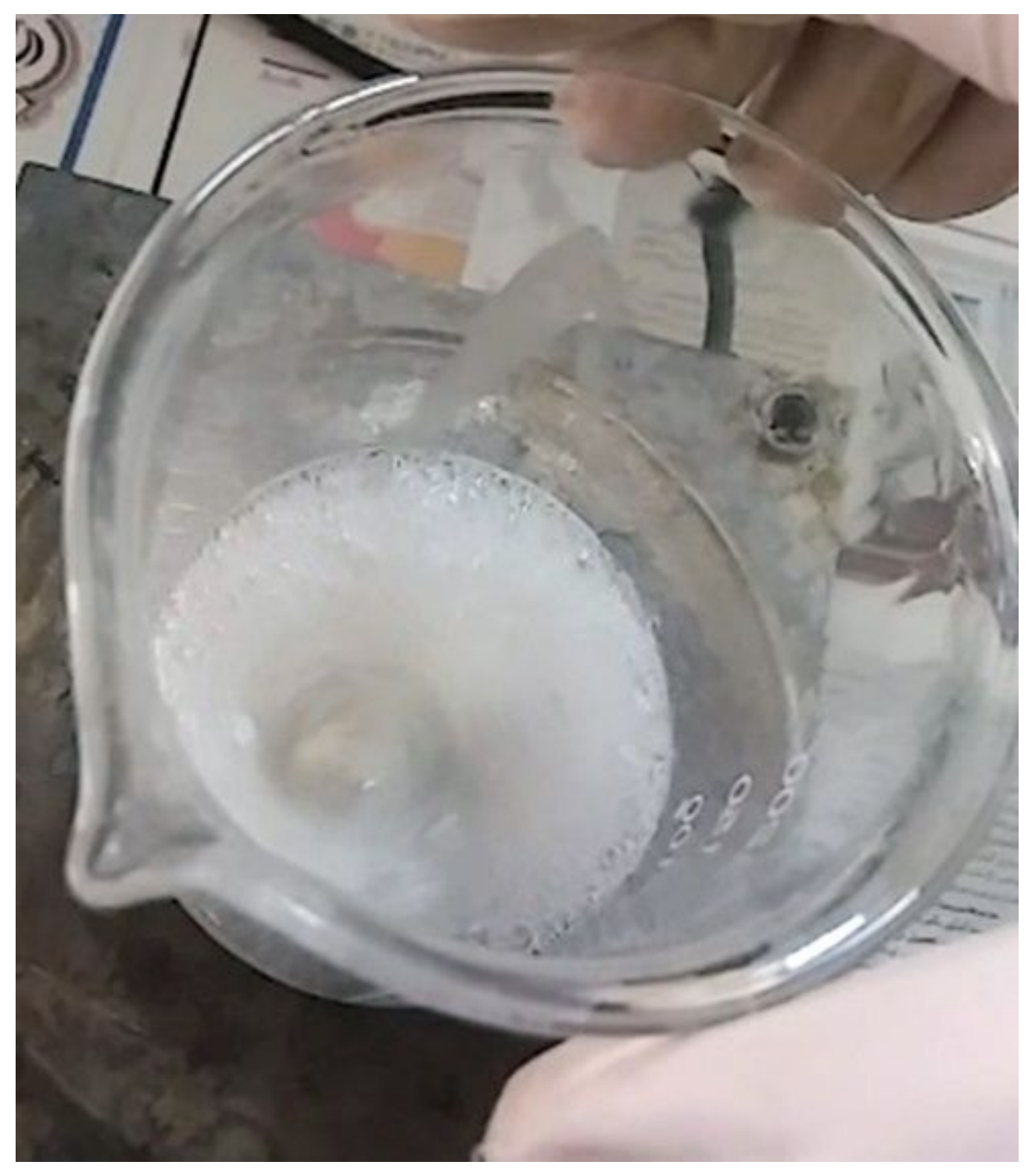

Figure 6

Dissolving polymer in propanone (acetone). 


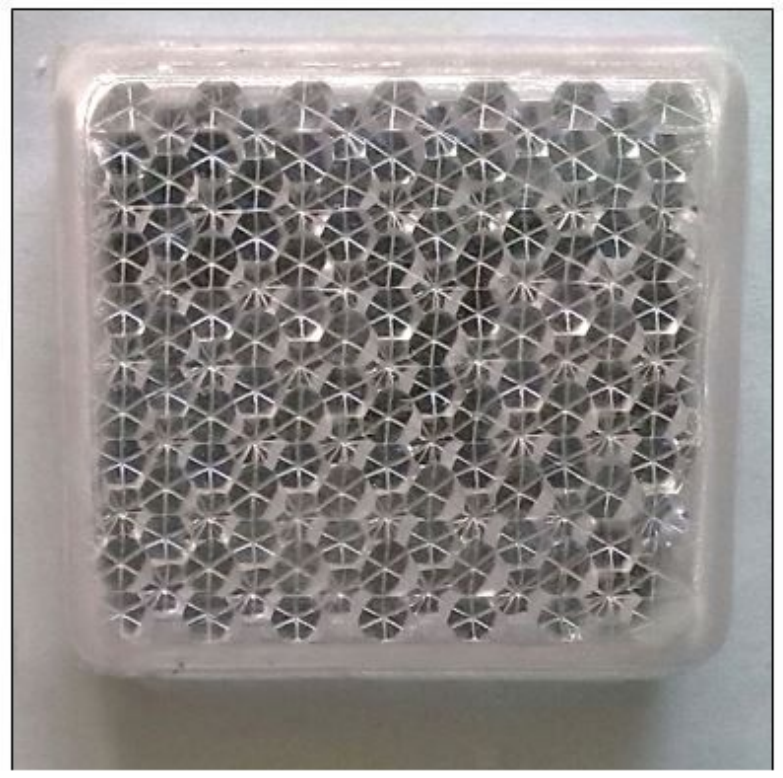

(a)

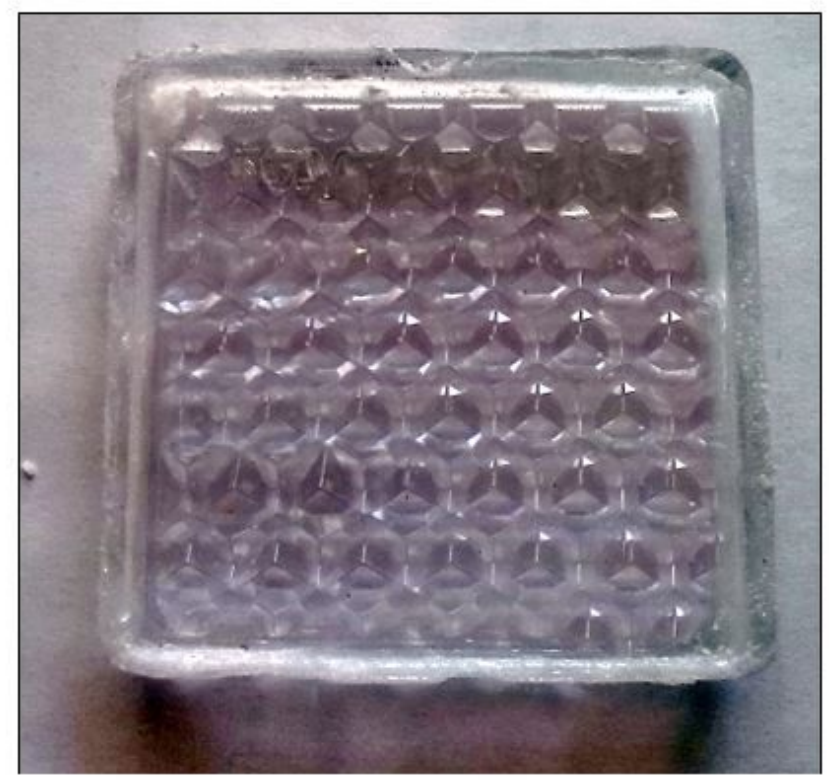

(b)

\section{Figure 7}

The assembled product; (a) external view; (b) Internal view (Dsiassembled)/

\section{Figure 8}

PMMA samples for contact angle test. 


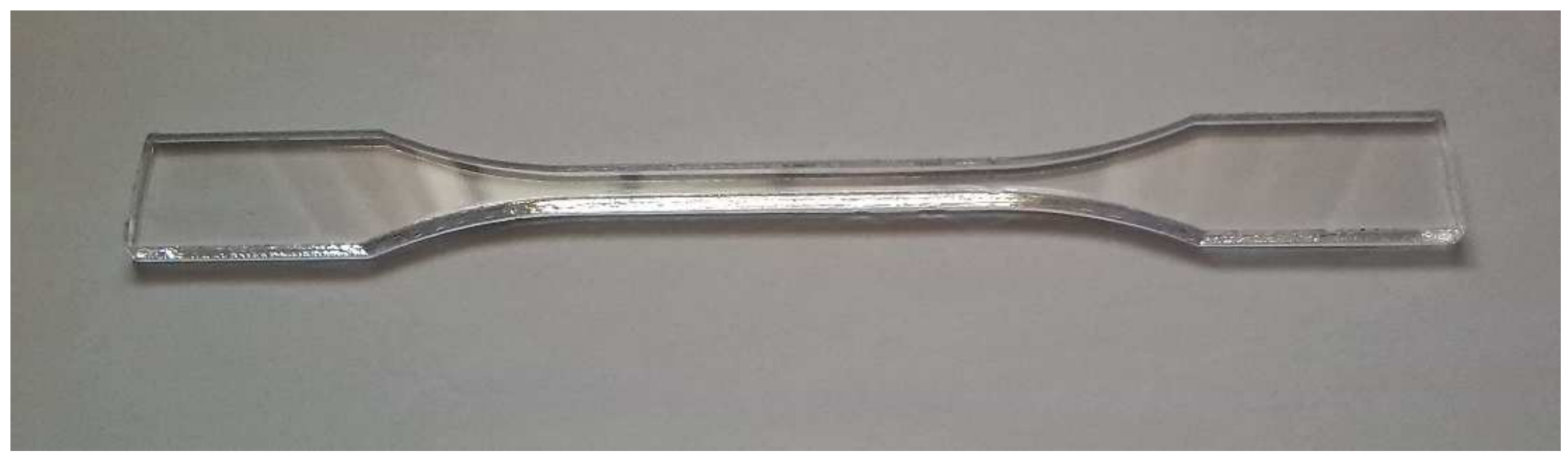

Figure 9

PMMA samples for tensile test.

Figure 10

PMMA samples for flexure test 


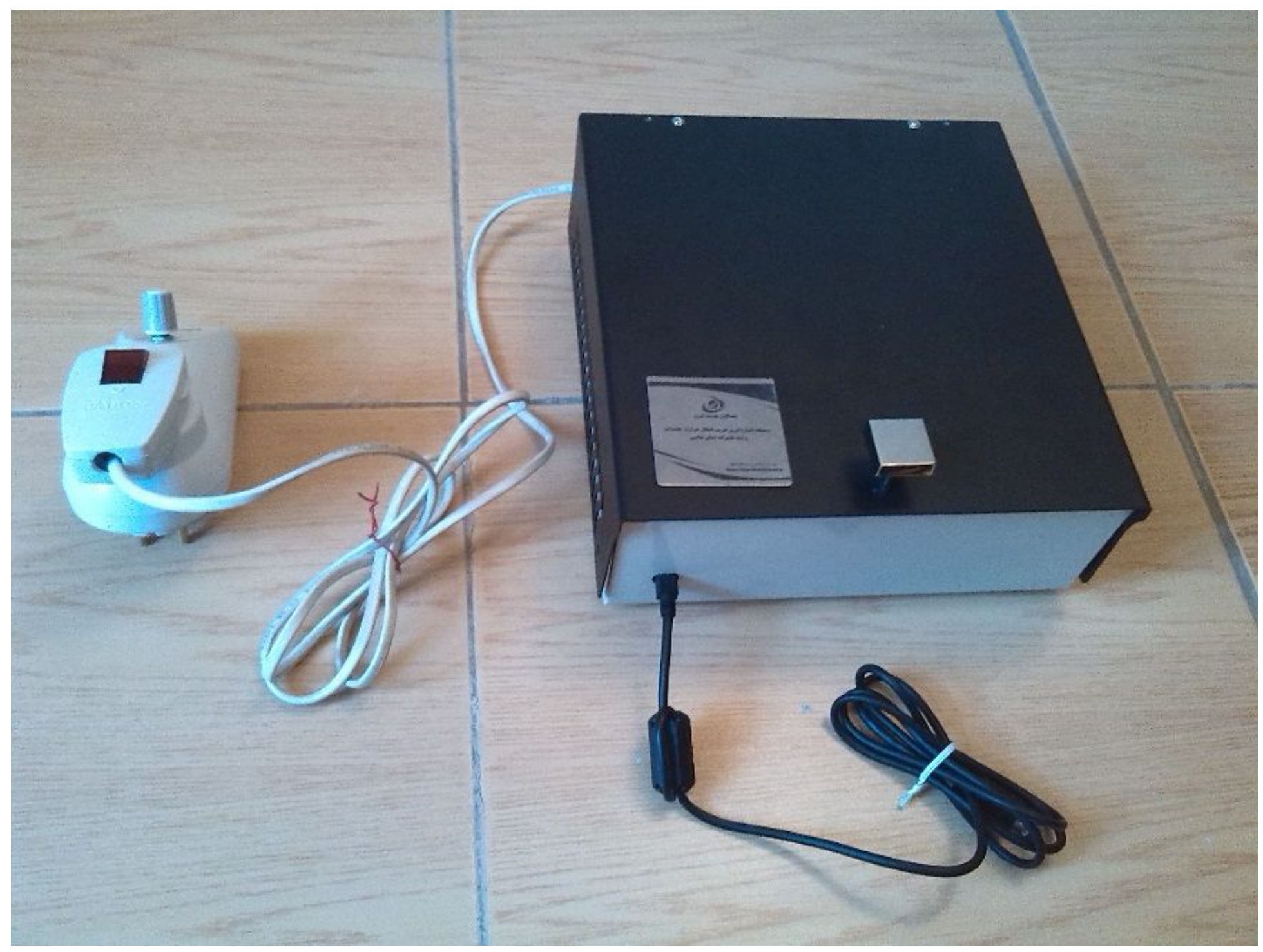

Figure 11

SDK TCC 001 Heat transfer conductivity measuring device used in experiments (Fabricated by author). 


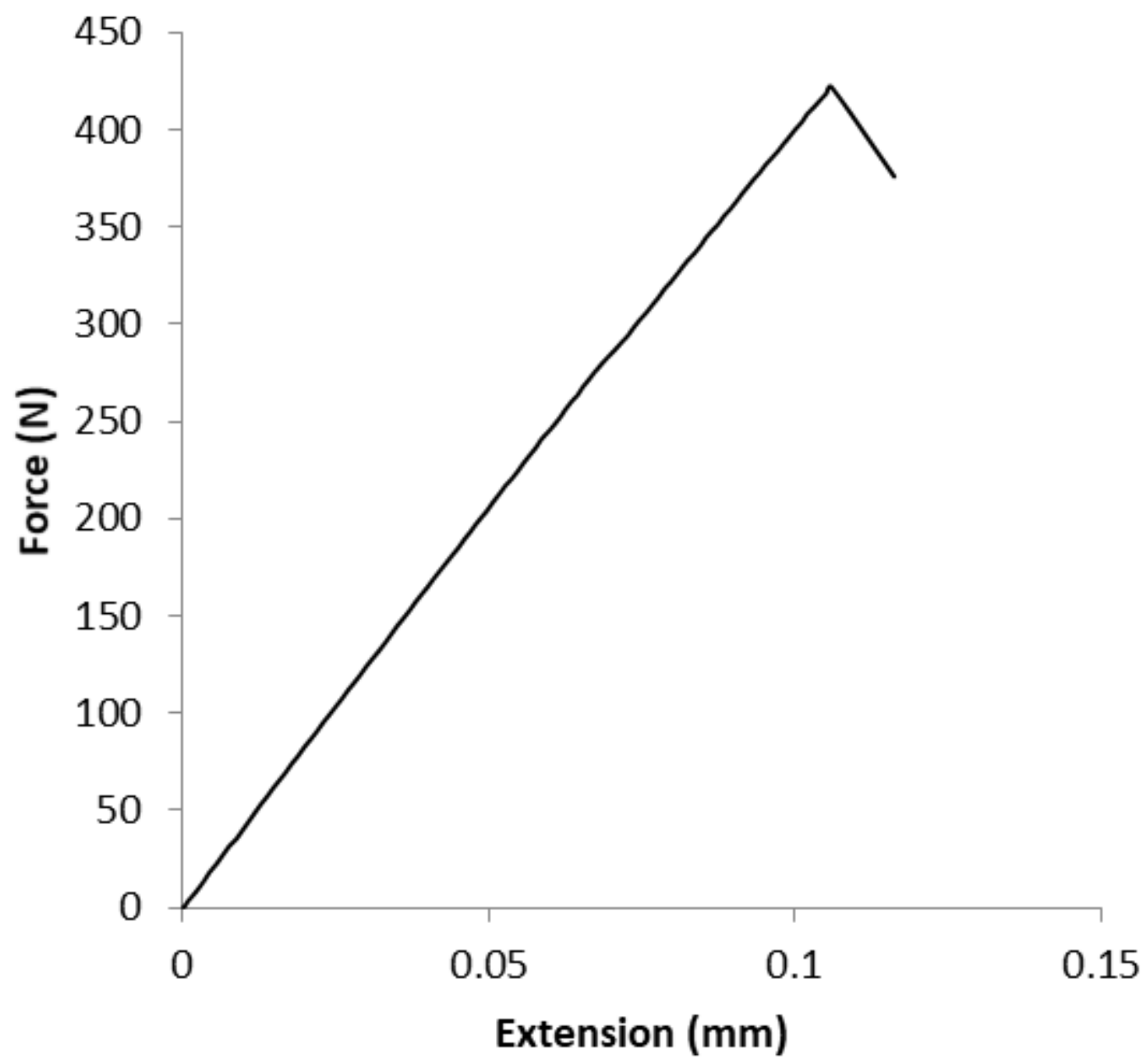

Figure 12

Polymeric sample tensile test results. 
Extension (mm)

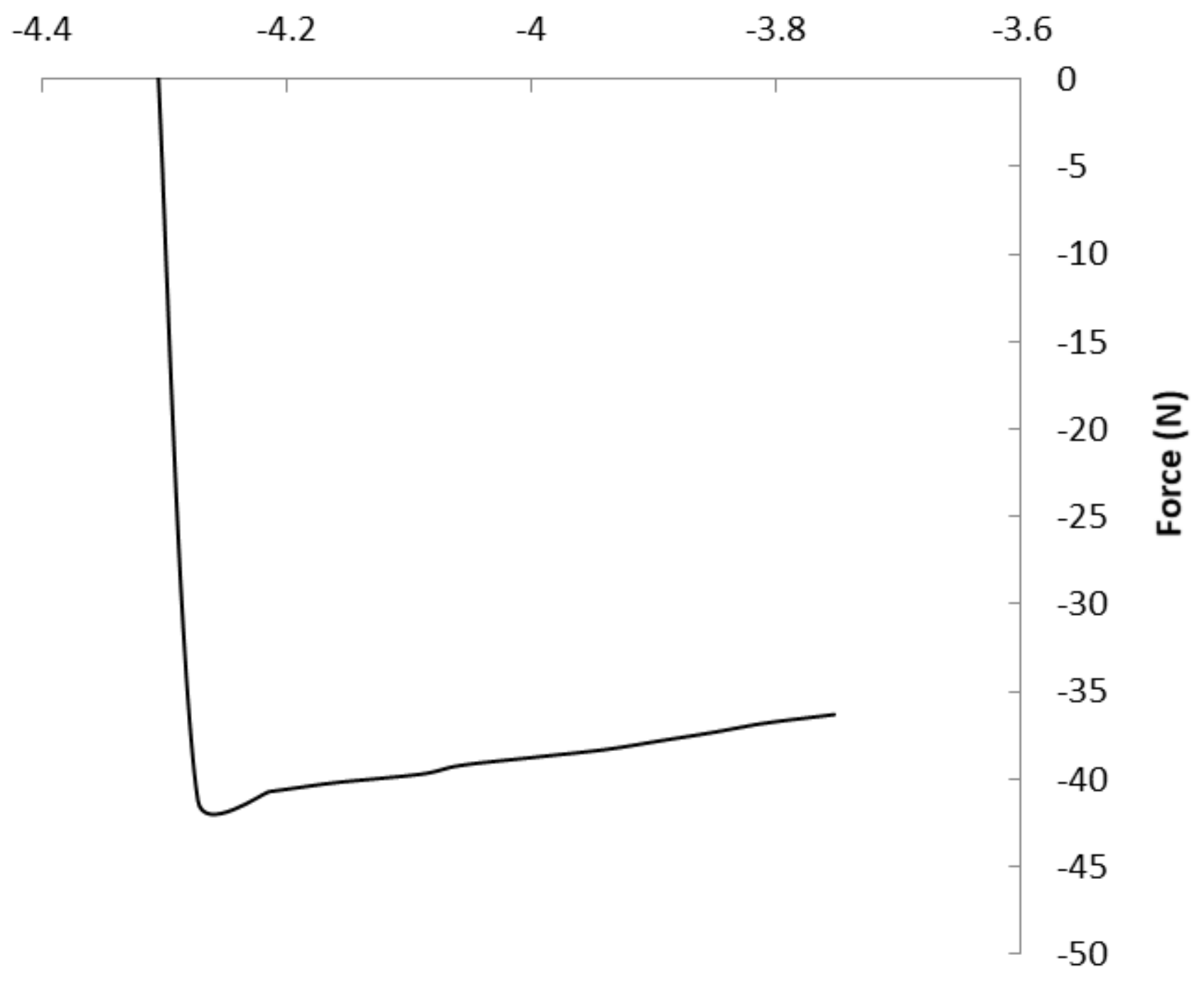

Figure 13

Polymeric sample flexural test results. 


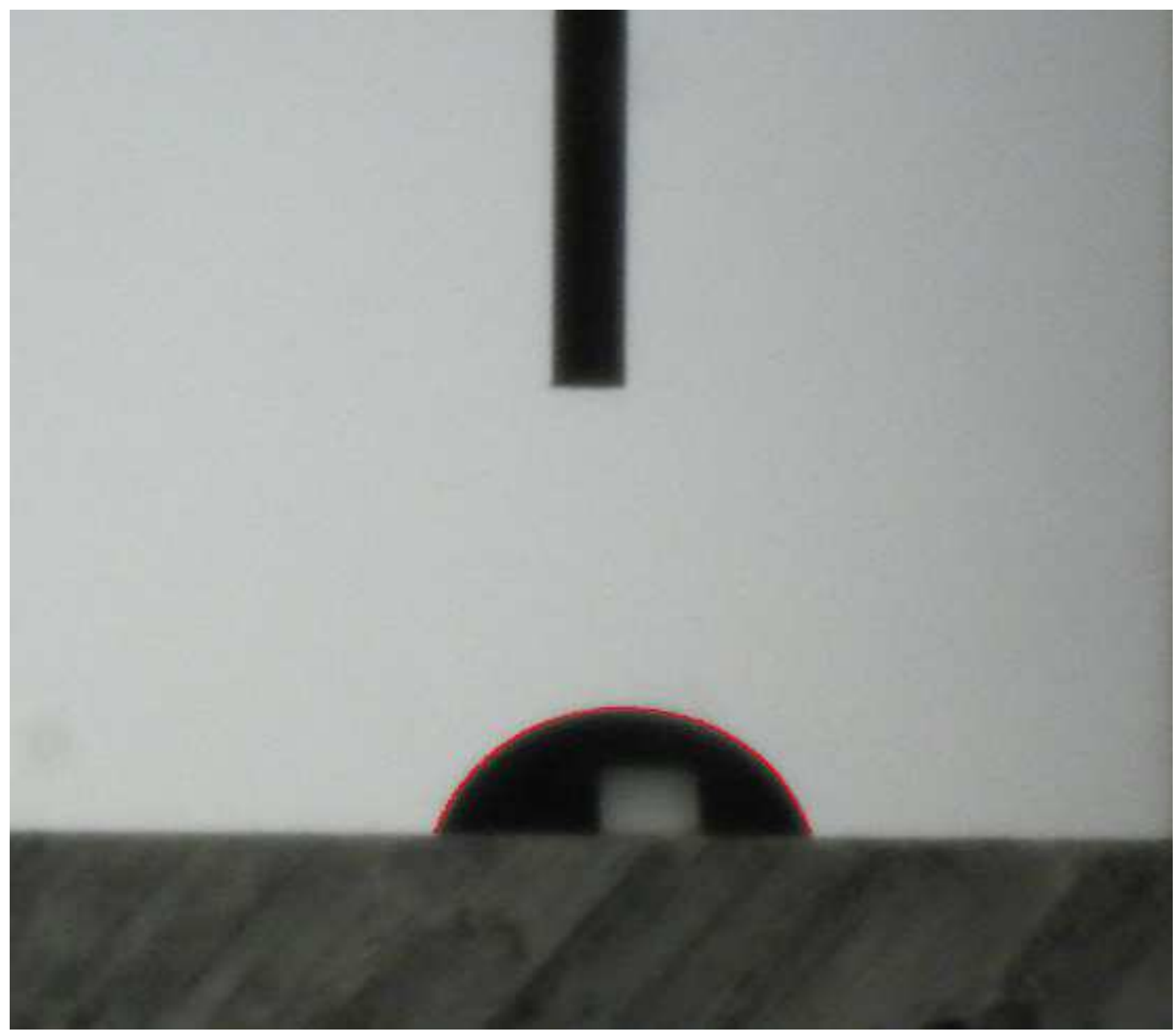

Figure 14

Photograph of a contact angle test between polymeric sample and water. 


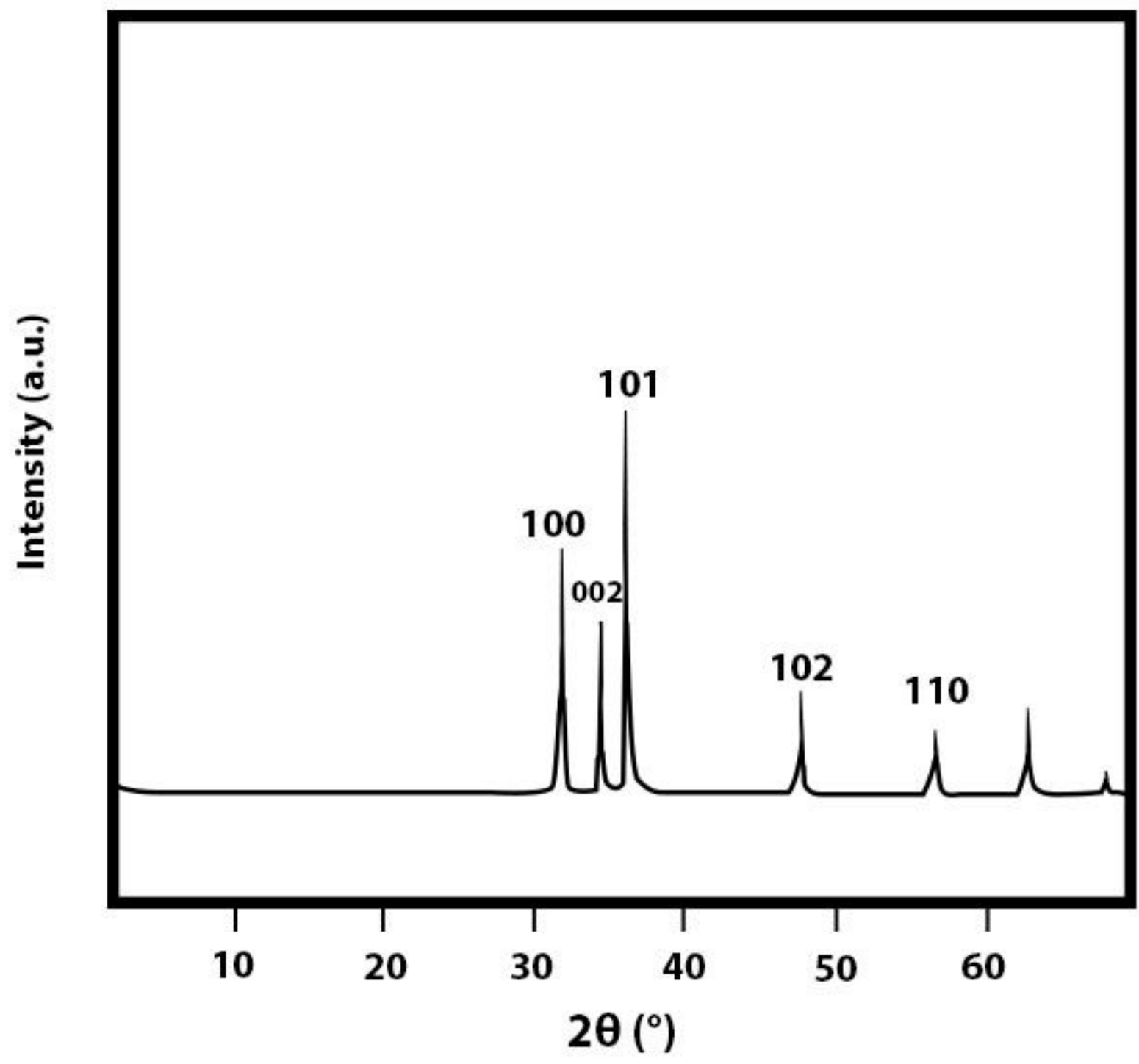

Figure 15

XRD patterm obtained for $\mathrm{ZnO}$ nano-particles with Ethanol. 


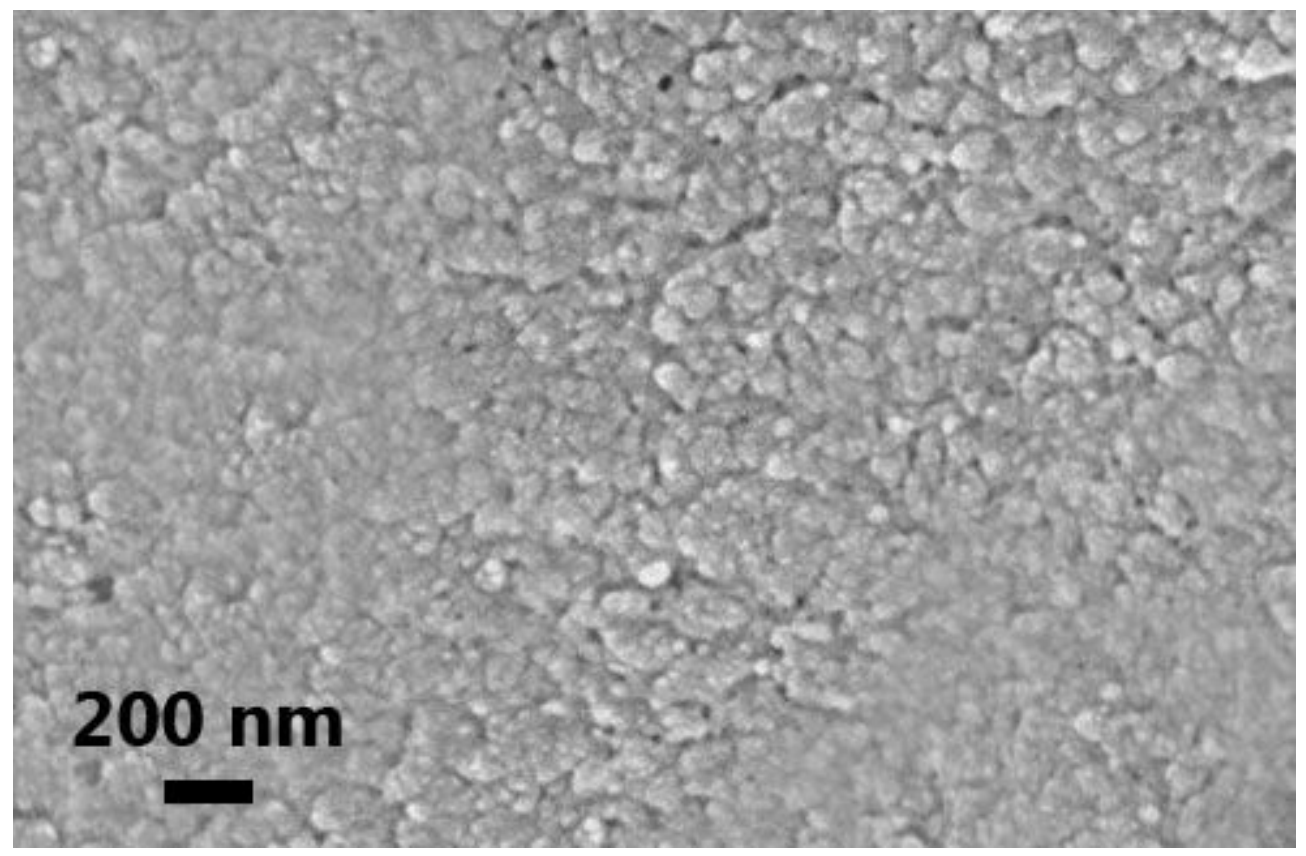

Figure 16

SEM photo obtained from Nano-composite film.

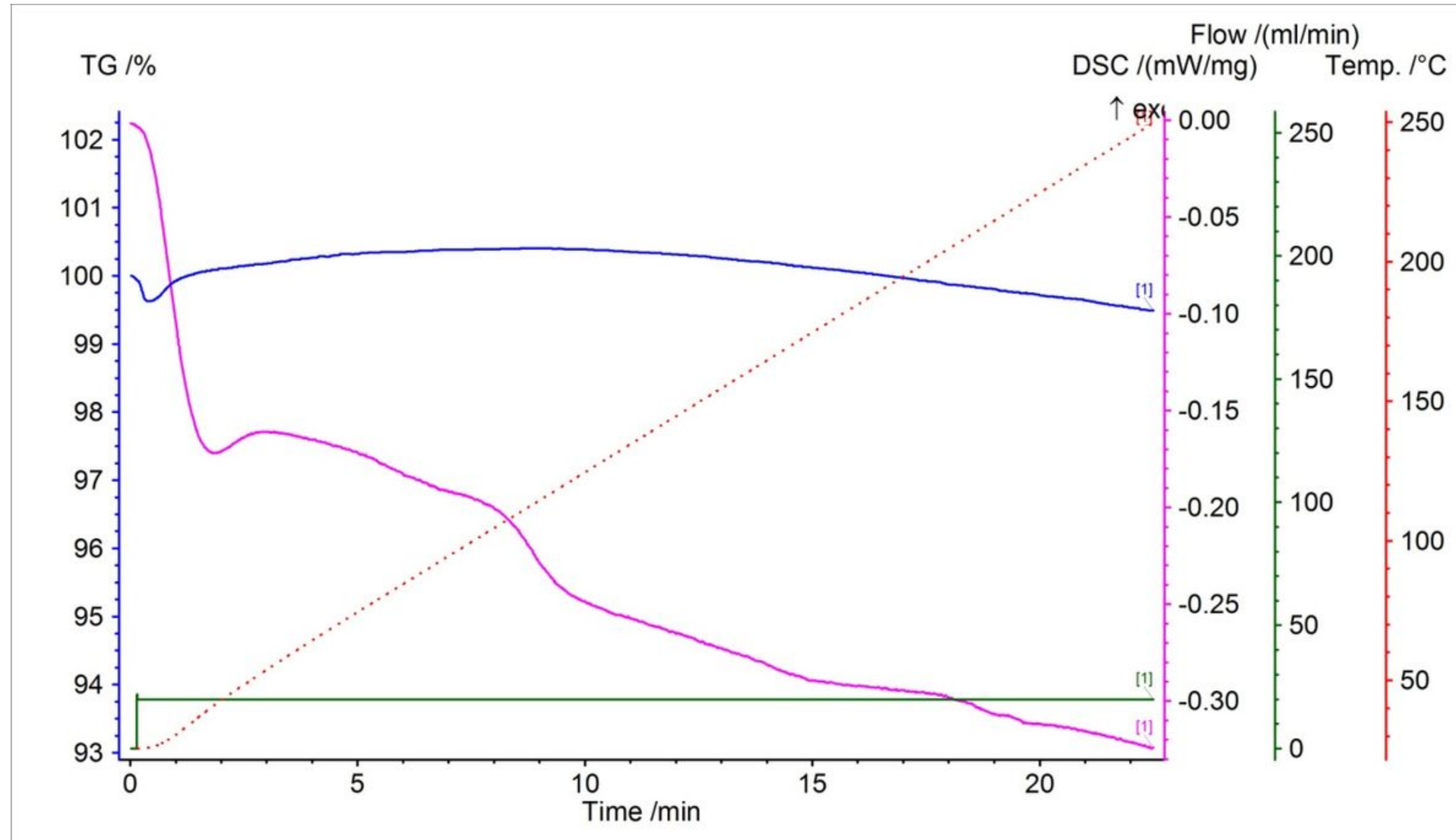

Figure 17

DSC test result on PMMA. 


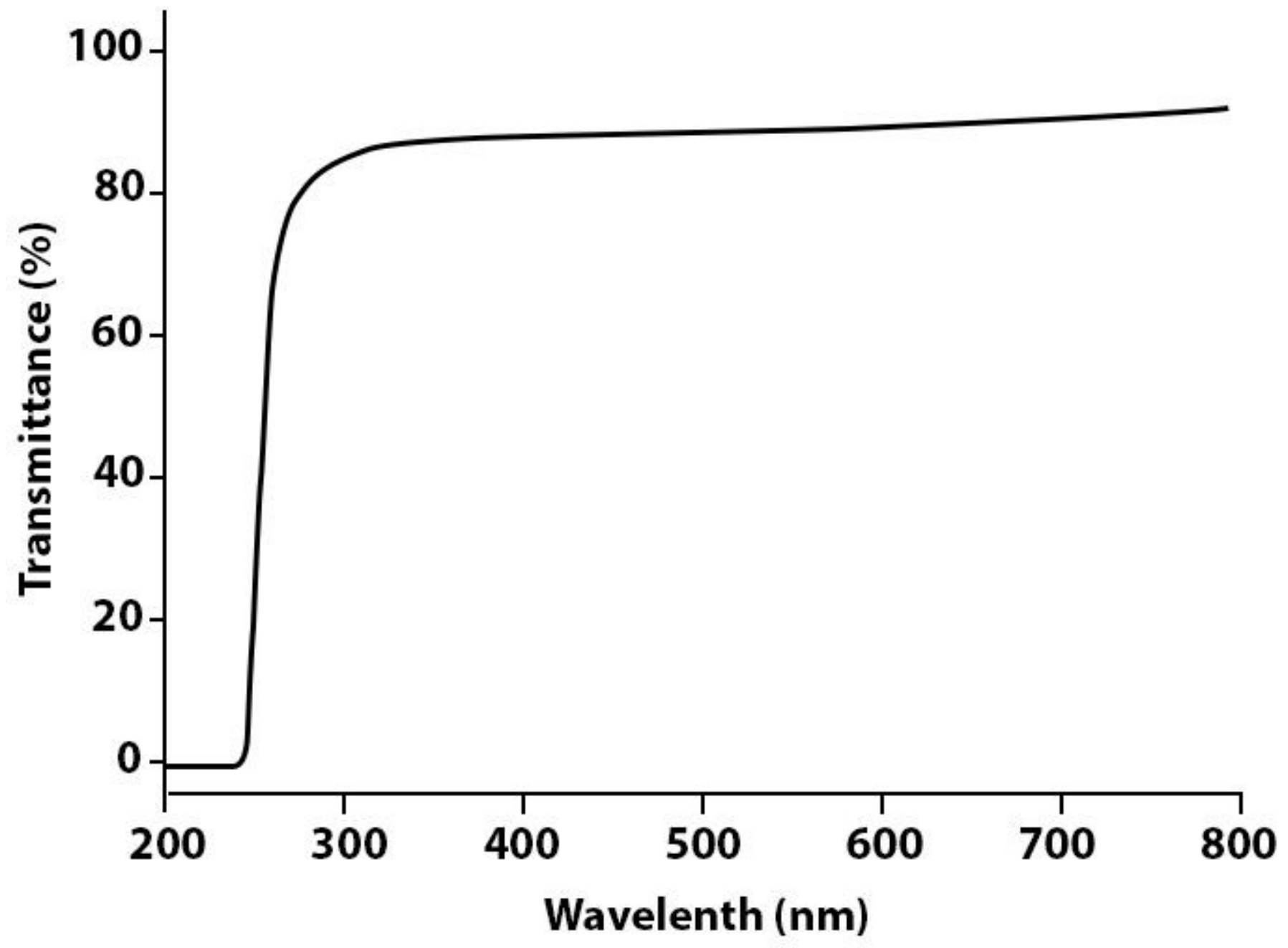

Figure 18

UV-Vis transmission curve, obtained for simple polymeric panels. 